Canadian Science Publishing

Canadian Journal of Earth Sciences Revue canadienne des sciences de la Terre

\title{
Tectonic and chemical implications of cathodoluminescent microstructures in quartz, Parry Sound domain, Ontario, Canada
}

\begin{tabular}{|r|l|}
\hline Journal: & Canadian Journal of Earth Sciences \\
\hline Manuscript ID & cjes-2016-0168.R2 \\
\hline Manuscript Type: & Article \\
\hline Complete List of Authors: & $\begin{array}{l}\text { Mills, Stephanie Gayle; University of Maine, School of Earth and Climate } \\
\text { Sciences } \\
\text { Gerbi, Christopher; University of Maine, School of Earth and Climate } \\
\text { Sciences } \\
\text { Marsh, Jeffrey H.; Queens College, School of Earth and Environmental } \\
\text { Sciences } \\
\text { Yates, Martin G.; University of Maine, School of Earth and Climate Sciences } \\
\text { Seaman, Sheila J.; University of Massachusetts Amherst, Department of } \\
\text { Geosciences } \\
\text { White, Joseph C.; Department of Geology }\end{array}$ \\
\hline Keyword: & \begin{tabular}{l} 
cathodoluminescence, quartz, microstructure, shear zone, Grenville \\
\hline
\end{tabular} \\
\hline
\end{tabular}

\section{SCHOLARONE}

Manuscripts 
Title: Tectonic and chemical implications of cathodoluminescent microstructures in quartz,

Parry Sound domain, Ontario, Canada

Authors: Stephanie G. Mills, Christopher Gerbi, Jeffrey H. Marsh, Martin G. Yates, Sheila J.

Seaman, Joseph C. White

S. G. Mills - corresponding author

stephanie.g.mills@maine.edu phone: 937-344-5222_fax: 207-581-2202

School of Earth and Climate Science, University of Maine, Orono, Maine 04469

C. Gerbi,

christopher.gerbi@maine.edu

School of Earth and Climate Science, University of Maine Orono, Maine 04469

Jeffrey H. Marsh

jmarsh@qc.cuny.edu

School of Earth and Environmental Sciences, Queens College, 65-30 Kissena Blvd Queens, New York 11367

M. G. Yates

yates@maine.edu

School of Earth and Climate Science, University of Maine Orono, Maine 04469

Sheila J. Seaman

sjs@geo.umass.edu

Department of Geosciences, University of Massachusetts Amherst, Massachusetts 01003

Joseph C. White

clancy@unb.ca

Earth Sciences, University of New Brunswick Fredericton, New Brunswick E3B 5A3 
Title: Tectonic and chemical implications of cathodoluminescent microstructures in quartz, Parry Sound domain, Ontario, Canada

Authors: Stephanie G. Mills, Christopher Gerbi, Jeffrey H. Marsh, Martin G. Yates, Sheila J. Seaman, Joseph C. White

Abstract: Cathodoluminescence (CL) imaging of quartz in orthogneiss of the Parry Sound domain, Grenville Province, Ontario, Canada reveals four dark microstructures - medium-dark grains, mantles, sinuous lines, and straight lines.. The Parry Sound domain experienced granulite-facies deformation and metamorphism followed by variable degrees of amphibolitefacies retrogression associated with the development of retrograde shear zones. We integrate our observations of CL-visible quartz microstructures with structures observable with optical and scanning transmission electron microscopy, analyses of water species concentration and trace element distribution in quartz, as well as with microstructures in plagioclase, to determine their characteristics and elucidate their timing and mechanisms of formation relative to the deformational history. Medium-dark grains are primarily located in and near kilometer-scale shear zones at the margins of the Parry Sound domain, have notably darker cores than most samples in the interior, and may have higher water contents than other samples in the interior. These grains formed during late shearing, at a lower temperature than CL-bright grains; they thus provide evidence that the large shear system narrowed with time. Dark mantles occur at grain boundaries and correlate with higher concentrations of Fe. They formed after the first shearing event, but while still at amphibolite facies, and they provide evidence for post-kinematic alteration at grain boundaries. Dark sinuous lines correspond to subgrain boundaries that formed after retrograde shearing, but while still at amphibolite facies. Dark straight lines correspond to 
fluid inclusion trails and most likely formed at low temperatures and pressures during exhumation.

Keywords: cathodoluminescence, quartz, microstructure, shear zone, Grenville 


\section{Introduction}

Middle to lower crustal rocks transmit stress from the lithospheric mantle to the surface, thereby affecting the earthquake cycle, topographic evolution, and overall tectonic activity of a region (e.g. Handy et al. 2007; Kearey et al. 2009; Koons et al. 2012). As a result, the compositional and structural information recorded in exhumed deep crustal rocks, typically granulites and amphibolites, has the potential to provide insight into their mechanical role in continental deformation. As a major component of continental crust, quartz likely plays a dominant role in controlling its rheological behavior (e.g. Brace \& Kohlstedt 1980, Handy 1990). The rheology of quartz has been extensively studied experimentally (e.g. Hirth and Tullis, 1992), quartz microstructures have been used in numerous studies to elucidate deformation history (e.g. Blenkinsop and Drury 1988, Rossetti et al. 2006), and cathodoluminescence (CL) has been widely utilized in sedimentary and hydrothermal studies (e.g. Boggs and Krinsley 2006, Rusk et al. 2008). However quartz microstructure as revealed by CL has been underutilized in microstructural deformation studies, particularly in high-grade rocks. CL imaging rapidly reveals slight variations in trace element composition that are difficult to detect by other means such as optically or with backscatter imaging. As a result, these CL microstructures can record otherwise cryptic microstructural and mineral chemical processes.

In this contribution, we document four types of CL-dark microstructures in quartz in high-grade orthogneiss - straight lines, sinuous lines, mantles (Fig. 1), and medium-dark grains that, to our knowledge, have not previously been thoroughly described from high-temperature metamorphic settings. We then consider the mechanisms and timing of the CL microstructures formation relative to other microstructural and metamorphic features in the studied rocks. This study is a part of an ongoing investigation of the tectonic and rheologic development of the 
kilometer-scale shear zones bounding the Parry Sound domain of the Central Gneiss Belt within the Ontario segment of the Grenville Province (cf. Culshaw et al. 2010, 2011; Gerbi et al. 2010; Marsh et al. 2011, 2013) and we use the quartz CL microstructures to provide an additional constraint on the regional tectonic history of this domain.

\section{Background}

\subsection{Geological Setting}

The Parry Sound domain, which lies within the Central Gneiss Belt of the Grenville Province, Ontario, Canada (Fig. 2), represents the high-grade basement of an arc system that collided with Laurentia ca. 1100 Ma (Culshaw et al. 1989; Carr et al. 2000 and references therein). The Central Gneiss Belt consists primarily of amphibolite- and granulite-facies thrust nappes that were transported northwestward and stacked just prior and during the Grenville Orogeny, 1100-980 Ma (e.g. Davidson et al. 1985; van Breemen and Hanmer, 1986; van Breemen et al. 1986; Culshaw et al. 1989; Carr et al. 2000; Rivers et al. 2012). The Parry Sound domain consists predominantly of mafic and felsic orthogneiss of both plutonic and volcanic origin, with subordinate paragneiss (Davidson 1984; Culshaw et al. 2004). It experienced a single episode of granulite-facies metamorphism, at $\sim 11 \mathrm{kbar}$ and $\sim 850^{\circ} \mathrm{C}$, ca. $1145-1160 \mathrm{Ma}$ (van Breemen and Hanmer, 1986; Wodicka et al. 2000; Marsh et al. 2012). Regional lithologic correlations suggest that during the collision, the Parry Sound domain traveled $\sim 100 \mathrm{~km}$ from its origin in the Composite Arc Belt (Wodicka et al. 1996, 2000; Culshaw et al. 1997; Carr et al. 2000 and references therein). Early in its tectonic history, the interior of the domain experienced intense deformation under granulite-facies conditions, producing the characteristic layered gneissic rocks of the central portion of the domain. At the time of its final emplacement, the Parry Sound domain had been partially exhumed and cooled to $\sim 6.5 \mathrm{kbar}$ and $700 \mathrm{C}^{\circ}$ such that 
the interior of the domain acted as a relatively strong, granulitic block (Wodicka 1996; Culshaw et al. 2010). Amphibolite-facies shearing was localized and took place at the domain margins took place at ca. $1100 \mathrm{Ma}$ (Wodicka et al. 2000; Marsh et al. 2011, 2013).

To the northwest, the $\sim 5 \mathrm{~km}$ wide Parry Sound shear zone separates the Parry Sound domain from the Shawanaga domain (Fig. 2). The Parry Sound shear zone formed in two strands that surround the basal Parry Sound domain; the upper strand formed under granulite-facies conditions, and was partially reactivated under amphibolite-facies conditions, whereas the lower strand developed under amphibolite-facies conditions (Culshaw et al., 2010). Between the two lies the basal Parry Sound domain, which comprises reworked and retrogressed rocks of the interior Parry sound domain. To the southeast, the $\sim 5 \mathrm{~km}$ wide Twelve Mile Bay shear zone separates the Parry Sound domain from the upper Go Home domain. Approaching the Twelve Mile Bay shear zone from within the Parry Sound domain, meter-scale shear zones increase in density and connectivity within the Zone of Reworking (Culshaw et al. 2010, Marsh et al. 2011; Fig. 3a), eventually becoming the dominant amphibolite-facies fabric in the Twelve Mile Bay shear zone, which persists over a thickness of $\sim 3 \mathrm{~km}$. These meter-scale shear zones originated under amphibolite-facies conditions as fractures in rocks with granulite-facies assemblages. The fractures filled with water-saturated magma; upon cooling, the magma crystallized into pegmatite, and exsolved water entered the host rock (Culshaw et al. 2010; Marsh et al. 2011), driving retrogression and formation of rheologically weaker amphibolite-facies assemblages. The meter-scale shear zones formed at high angles to the gneissic layering, with the pre-existing gneissic layering bending into and thereby defining the shear zones (Fig. 3a). Measured shear strains in these shear zones range up to 8 (Culshaw et al., 2011)."

Some $\mathrm{U}-\mathrm{Pb}$ zircon and $\delta^{18} \mathrm{O}$ data have been interpreted to suggest that the kilometer-scale 
Twelve Mile Bay shear zone narrowed over time, as the retrogression and shear fabric developed. Specifically, the core of the Twelve Mile Bay shear zone contains a few U-Pb zircon with ages of $1070 \mathrm{Ma}$ that are younger than those present within the meter-scale shear zones on the margin of the Parry Sound domain interior (ca. 1100 Ma; Marsh et al. 2012), suggesting that shearing activity persisted longer in the core or that the shear zone core was reactivated later. In addition, lower $\delta^{18} \mathrm{O}$ analyses in the core of the Twelve Mile Bay shear zone compared to those from the bounding meter-scale shear zones are consistent with either prolonged active shearing or later reactivation (Marsh et al. 2011). These observations imply but do not require that the shear-zone deformation and associated retrograde metamorphism became increasingly localized over time.

\subsection{Cathodoluminescence in quartz}

The CL signal originates from sample electrons that have been excited by secondary electrons when they return to a lower energy level, emitting energy in the form of light ( 400$700 \mathrm{~nm}) .$. Pure quartz tends to have low luminescence, whereas quartz with high concentrations of defects tends to luminesce brightly (e.g. Götze et al. 2001, van den Kerkhof et al. 2004). Moreover, quartz formed at high temperatures tends to luminesce more brightly due to the ability to incorporate higher concentrations of trace elements such as Ti under these conditions (Rusk et al. 2006; Spear and Wark 2009).

Because of the relationship between luminescence, trace element concentration, and temperature, CL has become a useful tool for investigating metamorphic and igneous rocks, with one of the main applications being identification of sites for Ti-in-quartz thermometry (Wark and Watson, 2006). The value of CL for constraining the timing and causes of metamorphic events has increased in the last twenty years, but still only relatively few studies have utilized the 
technique (e.g. Holness and Watt 2001; Harris et al. 2003; Muto et al. 2005; Spear and Wark 2009; Storm and Spear 2009; Bergman and Piazolo 2012; Spear et al. 2012; Ashley et al. 2013; Bufe et al. 2014).

\section{Sampling Strategy and Description of Samples}

We investigated samples from within amphibolite-facies shear zones (meter- and kilometer-scale), those from the immediately adjacent host rocks, and from "pristine" granulites that are unassociated with shear zones (Table 1). To simplify the terminology, for the purposes of this paper, we refer to the granulite rocks that existed prior to amphibolite-facies shear zone development as "protoliths" even though some samples show some signs of retrogression.

Because this study focuses on quartz microstructures, samples are from felsic layers from the interior Parry Sound domain and from kilometer-scale shear zones (Twelve Mile Bay shear zone and Parry Sound shear zone) as well as from one quartzite. We also examined mafic lithologies, but in addition to very little quartz present, the grains are very small $(<300 \mu \mathrm{m})$, and no features in the mafic samples affect the interpretations here. Thus, we do not report results from mafic rocks. Felsic samples from "pristine" granulites, protolith, and meter-scale shear zones typically contain large $(\sim 1-5 \mathrm{~mm})$ monomineralic aggregates with grain sizes $500 \mu \mathrm{m}$ to 3 $\mathrm{mm}$ consisting of quartz ( $40 \%)$ and feldspar ( $\sim 50 \%$ plagioclase, $\sim 4 \% \mathrm{~K}$-feldspar); samples also contain $\sim 6 \%$ orthopyroxene, hornblende, and/or biotite with less orthopyroxene in samples from meter-scale shear zones (Fig. 4). The quartz aggregates contain individual quartz grains that - in both protolith and sheared samples - typically have irregular and lobate grain boundaries, and planes of fluid inclusions. The majority of quartz grains with diameters $>300 \mu \mathrm{m}$ exhibit irregular subgrains. The quartz aggregates tend to be elongate in the direction of foliation, so aggregates in protolith—sheared pairs from the same layer are roughly orthogonal (Fig. 3b). 
Samples from kilometer-scale shear zones generally have similar bulk compositions except for containing hornblende and/or biotite instead of orthopyroxene, but tend to have smaller grain sizes $(\sim 100-400 \mu \mathrm{m})$..

Where the granulite-facies mineral assemblage is preserved, the rims of most orthopyroxene grains are altered to hornblende. A brown, unidentified phyllosilicate phase is also present in many fractures and along grain boundaries of orthopyroxene and hornblende. Plagioclase microstructures are described in section 5.

\section{Methods}

We collected CL images from carbon-coated samples using the panchromatic Tescan (350-650 nm) CL detector on the Tescan Vega XMU scanning electron microscope (SEM) in the School of Earth and Climate Sciences at the University of Maine. Images were captured with chamber pressures less than $10^{-2} \mathrm{~Pa}$. The best contrast in quartz CL was obtained with an operating voltage of $20 \mathrm{kV}$ and incident currents of 100-600 pA. Working distance was $\sim 15 \mathrm{~mm}$ and dwell time was typically $145 \mathrm{~ms} /$ pixel. We employed the following analytical techniques to explore the causes of the observed CL signal variation.

For scanning transmission electron microscopy (STEM), analyzed ion-milled foils of quartz using the JEOL 2011 STEM in the Microscopy and Microanalysis Facility at The University of New Brunswick. We obtained both bright field and electron diffraction images at an operating voltage of $200 \mathrm{kV}$ and a spot size of $15 \mathrm{~nm}$.

To collect Fourier transform infrared (FTIR) spectra of quartz, we used a Bruker Vertex 70 spectrometer and Hyperion 3000 IR microscope in the Department of Geosciences at the University of Massachusetts, Amherst. A globar light source, a KBr beam splitter and a DTGS (deuterated triglycine sulfate) detector were used. One hundred twenty-eight scans per spectrum 
were accumulated with a spectral resolution of $2 \mathrm{~cm}^{-1}$. The instrument is equipped with both an MCT (mercury cadmium telluride) single element detector that is used to collect spectra from discrete points, and a $64 \times 64$ focal plane array detector that is used to collect maps of areas of interest. For quantification of water contents, spectra were baseline corrected using a flexicurve generated with the software package OPUS of Bruker. The baseline is constructed by fitting a polynomial in the range of the total water peak (approximately $3700-2900 \mathrm{~cm}^{-1}$ ). Each pixel of a map corresponds to a $2.8 \mu \mathrm{m}^{2}$ area. Doubly polished sections $\sim 160 \mu \mathrm{m}$ thick were analyzed without glass or bonding agent so that transmission of the IR beam was through the sample only. The area under the IR spectrum band of interest was calculated using Bruker's OPUS software. The total water peak $\left(\sim 3700-2900 \mathrm{~cm}^{-1}\right)$ was used for calculating water concentration, and the peak at $\sim 2350 \mathrm{~cm}^{-1}$ was used to calculate $\mathrm{CO}_{2}$ concentrations. Concentrations of water measured in a single direction were calculated using the following Beer-Lambert Law modified from Libowitzky and Rossman (1997)

$$
\text { concentration }=\frac{1.8 \mathrm{~A}}{d \rho \varepsilon}
$$

where concentration is expressed in weight percent, $A$ is the area under the spectrum peak, $d$ is the thickness, $\rho$ is the density $\left(2.65 \mathrm{~g} / \mathrm{cm}^{3}\right), \varepsilon$ is the molar absorption coefficient $(24,100 \pm 1800$ $\mathrm{mol}^{-1} \mathrm{~cm}^{-2}$ for water species in quartz, from Stipp et al. 2006), 1.8 is a scaling factor so that hydrogen is expressed in water equivalents. Molar absorption coefficients for carbon dioxide in quartz are not available; however, relative concentrations are relevant to the present study. Libowitzky and Rossman (1996) demonstrated that it is necessary to collect spectra in three mutually perpendicular orientations to measure water species concentrations by FTIR spectroscopic analysis of crystalline materials. Because of the relatively small anisotropy of water concentration in quartz crystals, we have multiplied measured water concentrations by 
three to approximate total crystal water concentrations. Propagation of error estimates in determining the IR band areas $( \pm 10 \%)$, in molar absorption coefficients $( \pm \sim 10 \%)$, and sample thickness $( \pm \sim 1 \%)$ through equation 1 yields total accuracy estimates of $\pm \sim 21 \%$ for total water in crystals. On the basis of known anisotropy of quartz crystals we estimate the total uncertainty in our water concentration measurements at $\pm 30 \%$.

We carried out wavelength dispersive electron microprobe analysis (EPMA) on the Cameca SX-100 at the University of Maine School of Earth and Climate Sciences. We measured $\mathrm{Ti}$ and Fe concentrations in quartz using the TiK $\alpha$ and $\mathrm{FeK} \alpha$ with rutile and pure Fe standards, respectively. Settings were as follows: operating voltage of $15 \mathrm{kV}$, spot size of $5 \mu \mathrm{m}$, beam current of $150 \mathrm{nA}$, background count time of $150 \mathrm{~s}$ above and below the peaks, peak count time of $300 \mathrm{~s}$. We used measured rather than theoretical detection limits (DL), calculated as two standard deviations using the following formulation:

$$
D L=\frac{(\% \text { element in std })(\text { standard deviation of bkg cps })(Z A F)}{\text { peak cps in std }}
$$

where std denotes standard, bkg denotes background, cps is counts per second, and ZAF is a matrix correction which we set as 1 . Some data points were removed due to two types of contamination. The first type is contamination by inclusions which were identified by concentrations $\sim 2 \mathrm{x}$ greater than the majority of other values in the data set. The second type is contamination from other CL microstructures; for example if an analysis spot was on a CL-dark microstructure while analyzing CL-bright cores. 


\section{Quartz and Plagioclase microstructures}

\subsection{Cathodoluminescence}

Based on CL imaging, we define four types of quartz microstructures that are common across the study area; all are dark microstructures on a bright core. Their CL signals are quantitatively lower, as determined by imaging dark microstructures (including medium-dark grains) and bright cores (e.g., Fig. 1) under the same operating conditions and brightness/contrast settings. Here we first describe each microstructure, then consider correlationswith the results of other analytical techniques.

\subsubsection{Medium-dark grains}

In the samples with medium-dark grains, most or all of the quartz grains are quantitatively darker than the bright cores of the majority of samples studied. They tend to be uniform in shade or have a diffuse patchy quality. Because some medium-dark grains also exhibit mantles (Fig. 5), we do not consider the medium-dark attribute to represent an unusually wide mantle. Many of the samples containing medium-dark grains have an overall finer grain size with the quartz dispersed rather than occurring in polycrystalline aggregates. Medium-dark grains are primarily found in samples from within or near kilometer-scale shear zones (Fig. 2).

\subsubsection{Mantles}

CL-dark mantles in quartz typically exhibit an abrupt transition from CL-bright cores (Fig. 1, 3c,d). They are present in quartz grains in nearly all samples and include a few completely medium-dark grains (Fig. 5). In contrast to the line microstructures in quartz discussed below, they also occur in small $(<200 \mu \mathrm{m})$ grains. . In many grains, the mantles exhibit a width of $\sim 100 \mu \mathrm{m}$ (quantified in a later section), though the width varies due to the irregular morphology. This irregular morphology is similar in both protolith and sheared samples (Fig. 
$3 \mathrm{c}, \mathrm{d})$.

Intragranular dark patches are found in a few grains and share similar width and morphology with mantles (Fig. 6), and surround fluid inclusions.

\subsubsection{Sinuous Lines}

Sinuous lines luminesce dark on bright cores (Fig. 1, 7), and in a few locations they luminesce bright on dark mantles. Though we use the term "lines" for brevity, they are in reality curviplanar surfaces that express themselves as curvilinear features when viewed on a planar section. The sinuous lines are $\sim 2 \mu \mathrm{m}$ wide and are much more curved and kinked than the straight lines; they typically interconnect, forming enclosed areas within a grain (Fig. 1). They are present in all large $(>300 \mu \mathrm{m})$ grains we examined in both protolith and sheared samples. Although the density of sinuous lines is spatially heterogeneous, we observe no systematic difference across structural settings.

\subsubsection{Straight Lines}

Straight lines are typically $\sim 5-10 \mu \mathrm{m}$ wide and distinctly cut bright cores (Fig. 1). Though we use the term "lines" for brevity, they are in reality planar structures that express themselves as lines when viewed on a planar section. In most areas where they intersect mantles, they are typically indistinguishable from the mantle; in a few locations, the straight lines are darker than the mantle. Straight lines are intragranular features that run from grain boundary to grain boundary, but somecross only part of a grain. Most are fairly straight with only gentle curves. As with the sinuous lines, they are present in all grains $>300 \mu \mathrm{m}$. Qualitatively, there is no significant difference in the spatial distribution of straight lines across structural settings.

\subsubsection{Feldspar Microstructures}

In felsic samples, feldspar exists in three dominant styles: large $(>2 \mathrm{~mm})$ antiperthite grains (Fig. 8a), large antiperthite grains mantled by small $(\sim 200 \mu \mathrm{m})$ polygonal plagioclase (Fig. 
$8 b)$, and medium $(\sim 600 \mu \mathrm{m})$ equant, polygonal plagioclase grains (Fig. $8 \mathrm{c})$. The large grains are found exclusively in protolith and "pristine" granulite samples, and thus are relict. The small plagioclase grains have brighter CL than the large grains they mantle, but the populations do not have significantly different major element compositions based on reconnaissance energy dispersive spectroscopy analysis. Note that Marsh et al. (2011) found a difference in major element chemistry of plagioclase between protolith and sheared samples, however within a single sample, we do not find any difference between relict and recrystallized grains with different CL signals. Both relict and recrystallized plagioclase grains from "pristine" granulites, protolith, and sheared samples have a wide, diffuse rim of brighter CL (Fig. 9), but there is no marked major element difference between rims and cores, so we interpret the different CL intensity to be a result of a variation of trace element concentrations.

\subsection{Light microscopy}

Under light microscopy, quartz, relict plagioclase, and recrystallized plagioclase contain fluid inclusion planes that cut across the entire grain. Nearly all CL straight lines in quartz correspond to fluid inclusion planes (Fig. 10).

The majority of large (>300 $\mu \mathrm{m})$ quartz grains exhibit irregular subgrains (Fig. 7). We use the term "subgrain" to denote an intragranular misorientation and do not imply a particular mechanism of formation. The majority of optically visible subgrains correlate with CL sinuous lines, but not all sinuous lines have a clear optical counterpart.

No optically visible features correlate with the mantles. Changes in extinction and subgrain boundaries do not correlate with mantles, nor are they patches of small grains. No consistent correlation exists between mantle location and fluid or solid inclusion concentration. 


\subsection{STEM}

We imaged two foils from a thin section of a sheared sample (GB9C) with bright field STEM to determine whether subgrains were likely formed by subgrain rotation or fracturing (den Brok et al. 1998). We chose this sample because it is a quartzite and has a high density of sinuous lines guaranteeing that many foils could be made containing sinuous lines in quartz. We did not analyze more samples due to the intensive sample preparation procedure and because the observations of the two foils were similar. Many subgrain boundaries have the typical "picket fence" appearance of regularly spaced dislocations (e.g. Mainprice et al. 1986); they tend to be curved and interconnected (Fig. 11). A lesser number of healed fractures are also present.

\subsection{FTIR}

We employed FTIR to measure concentrations of water species $(-\mathrm{OH}$, and structurally bound $\mathrm{H}_{2} \mathrm{O}$ ) and $\mathrm{CO}_{2}$ in a protolith—shear pair GB38A, GB38B. These samples include medium-dark grains and are the only samples with wide, diffuse mantles which we interpret as the beginning stages of the formation of full medium-dark grains. Because some grains still have a portion of bright core, we can directly compare water content in bright cores and the mediumdark structure. We did not analyze samples with the sharp mantle structure because of the difficulty distinguishing whether the water signal is from the grain boundary or the mantles in the thick samples required for FTIR analysis. The $\mathrm{CO}_{2}$ maps of quartz are fairly uniform, so there is no correlation between $\mathrm{CL}$ microstructures and $\mathrm{CO}_{2}$ content. Water species maps show heterogeneous water concentrations (Fig. 12). Where present, straight lines correlate with higher water content, consistent with the presence of fluid inclusions. The spatial resolution is not sufficient to test whether a correlation exists between water content and sinuous lines. Unfortunately, little of the analyzed area can be isolated to investigate the relationship between 
structural water and the CL intensity because very little of the quartz is free of fractures, fluid inclusions, and grain boundaries. The area shown in Fig. 12 (protolith sample GB38A) is the FTIR scan with the only sizable uncontaminated, medium-dark areas, so is the only scan we discuss. The majority of uncontaminated areas in the bright core have concentrations below 185 ppm. A relatively larger percentage of uncontaminated area within the medium-dark region has concentrations greater than $370 \mathrm{ppm}$. However, the medium-dark areas also have sizeable patches of $<185 \mathrm{ppm}$ water species and the total area of mantle analyzed is very small. We therefore consider higher water content likely to correlate inversely with CL intensity, but cannot verify a robust correlation due to limited medium-dark area available for analysis.

\subsection{Trace Elements}

We attempted to determine the trace element concentration variation across the different CL microstructures using LA-ICP-MS. However, due to the spatial resolution, the data do not provide accurate measures of the trace element content (Mills, 2015). We therefore analyzed sample GB61G, a protolith sample near a meter-scale shear zone, with EPMA, carrying out two transects for Fe concentration and three for Ti concentration (Table 2); we did not analyze more samples because of the low Ti concentrations, and because of the lack of evidence for measurable variation in Fe concentrationsbetween samples. The Ti results are at or below the detection limit for EPMA analysis (8-22 ppm), so we cannot establish whether a correlation between Ti and CL intensity exists. Measured concentrations of Fe are near the detection limit in the core and above detection limit for most of the mantle (Table 2). The measurable difference in Fe concentration between the core and mantle suggests a negative correlation of Fe concentration with CL intensity and thus that Fe is a likely CL quencher. 


\subsection{Effective Mantle Width}

A visual inspection of all protolith—sheared pairs suggests that the mantle width does not change systematically between the two. We sought to test this optical observation with quantitative measurements of two pairs. Because of the nature of the boundaries, the mantles had to be hand-traced, limiting our sample set. The chosen samples are the only protolith-shear pairs in our sample set from the same layer with clearly defined mantles in all grains.

To quantitatively test whether mantle widths vary between protolith and sheared samples, we developed the following methodology to calculate an average mantle width:

$$
\text { average width }=\frac{\text { mantle area }}{\text { perimeter }}
$$

where the perimeter is measured at the boundary between quartz and other minerals. We tested this method on artificial geometries and found deviation to be less than $15 \%$ from the true value. Because of the variability in greyscale of mantles in CL images and because mantles are intersected by equally dark sinuous and straight lines, we could not automate the process of identifying mantle versus core or dark neighboring grains, and hand-traced images were digitized for measurement.

Results are in Table 3 . In one pair, the protolith mantles are wider by $29 \%$, and in the other sample, the sheared mantles are wider by $7 \%$. Many more measurements are needed to perform statistical tests, but from the limited dataset, we can conclude that the mantle widths do not uniformly diminish significantly from the protolith to sheared samples. Even if we take the higher percentage thinning as the rule, that amount of thinning is markedly less than expected for the bulk shear strains in the sheared samples (Culshaw et al., 2011). If quartz shape change were to match the bulk strain, we would expect mantle widths to decrease by $>50 \%$ 


\subsection{CL intensity}

We took at least one CL image from each sample under the same beam and brightness/contrast settings in order to compare the absolute brightness of quartz cores. Cores of quartz within pristine granulites luminesce at the same levels as the cores of grains formed during amphibolite retrogression, including those in quartz-hornblende aggregates after orthopyroxene and in the meter-scale shear zones. This suggests that absolute luminescence did not change appreciably across a range of high temperature $\left(650^{\circ} \mathrm{C}-850^{\circ} \mathrm{C}\right)$ conditions.

\section{Discussion}

In this section, we interpret the mechanisms and timing of the microstructures and discuss their significance with respect to the rheological evolution of the kilometer-scale shear zones surrounding the Parry Sound domain. The methods in addition to CL by which each quartz CL microstructure is visible are summarized in Table 4.

\subsection{Mechanisms}

\subsubsection{Medium-dark Grains}

All samples with medium-dark grains are located within (GB50D,H; GB2B) or near (GB38A,B; GB6E,G; GB21L; B1-4A; and GB90A) amphibolite-facies shear zones, (Fig. 2). Whereas GB38A,B, and GB6E,G at Matches Island (M, Fig. 2) are a few kilometers from the core of the Twelve Mile Bay shear zone, there is evidence for a local young shearing event (Regan et al., 2014; Culshaw, personal communication, 2015). B1-4A, GB90A, and GB21L lie adjacent to meter-scale amphibolite-facies shear zones (Thompson, 1983; Culshaw et al., 2010). Several of these samples have fine-grained, dispersed-phase textures that are indicative of a high degree of strain and recrystallization (cf. Kilian et al. 2011). FTIR results suggest that higher water contents likely correlate with the medium-dark structure, consistent with amphibolite- 
facies hydration. Thus, we interpret all medium-dark microstructures to have formed during recrystallization at amphibolite-facies conditions.

\subsubsection{Mantles}

The chemical and physical analyses do not lend themselves to clear interpretation of a mechanism of formation. There is no apparent correlation between mantles and optically visible properties such as extinction patterns or the presence of fluid inclusions. We cannot confirm that our STEM analyses covered any area of the mantles, so we are unable to test correlation with structural features such as dislocation density. EPMA results indicate that Fe exhibits an inverse correlation between CL intensity and and Fe concentration, possibly suggesting that the dark mantles are the result of quenching of the CL signal by this element.

To narrow down the possible mechanisms of formation of the dark mantles, we compared them with another microstructure of similar morphology and width that also occur in our samples and have been described in the literature - intragranular dark patches (Fig. 6). Due to similarities between mantles and intragranular dark patches, we suggest that they formed by similar mechanisms. Literature interpretations of intragranular dark patches posit an origin related to fluid inclusions, either due to recrystallization (van den Kerkhof et al., 2004) or to a dissolutionreprecipitation mechanism (Lambrecht and Diamond, 2014). Both mechanisms suggest that the relatively small amount of fluid in the inclusions is sufficient to form the much larger dark patches. Parry Sound mantles are not presently associated with fluid inclusions, so we suggest that mantles may have formed from small amounts of water remaining at grain boundaries in a recrystallization and/or dissolution-precipitation mechanism. An alternative origin by diffusion is not favored because this process tends to form rims of approximately constant width all around the grain, and leads to a gradient in CL intensity (e.g. Spear et al. 2012), features that are not 
compatible with the irregular morphologies and sharp boundaries of the mantles observed in our samples (fig. 3c,d). In conclusion, we cannot definitively deduce the mechanism that caused the dark mantles, except to note literature interpretations of the possibly related dark intragranular patches suggest that water was involved.

\subsubsection{Sinuous lines}

Comparisons of CL and optical images (Fig. 7) show that the sinuous CL-dark lines correlate with subgrain boundaries. Spot checks of lattice mis-orientations across these boundaries using electron backscatter diffraction show that most are $<3^{\circ}$. In our STEM analysis, we found that typical subgrain boundaries are much more pervasive than healed fractures and that they are curved and networked in a manner similar to the CL sinuous lines. Therefore, similar to Götze (2009), Bestman et al. (2016), Hamers et al. (in press), we interpret the sinuous lines as subgrain boundaries formed during rotation recrystallization. .

\subsubsection{Straight lines}

The straight lines correspond to fluid inclusion planes that are visible optically (Fig. 10), which we interpret as healed or sealed fractures (e.g. Tuttle 1949).

\subsection{Timing}

6.2.1 Evolution and relative timing of CL microstructures in quartz

In order to provide context for the timing of each of the CL microstuctures in quartz, we first discuss the general microstructural evolution of the samples. Most meter-scale shear zones have a foliation roughly orthogonal to protolith foliation (Fig. 3a), so the quartz aggregates (which are elongate in the direction of foliation) change their orientation by $\sim 90^{\circ}$ during the amphibolite-facies shearing event. Also, many quartz aggregates in sheared samples are more 
elongate than their protolith counterparts. Therefore, quartz aggregates and their constituent grains experienced both an orientation and shape change during amphibolite-facies shearing (Fig. $3 b)$. These changes require recrystallization, a process which is consistent with the inferred amphibolite-facies temperature range of deformation of approximately $640-710^{\circ} \mathrm{C}$ (Marsh et al. 2011, 2013).

In the following sections, we test predicted differences between protolith and sheared samples for three possible times of formation of the quartz microstructures, i.e., pre-, syn- or post-retrograde shearing. (i) If any of the CL microstructures were present before the shearing event, we would expect them to be strongly modified or completely erased in the sheared samples because quartz recrystallized during shearing . (ii) If the microstructures formed during shearing-related shape/orientation change, we would expect some difference - such as greater width of mantles - in the sheared samples compared to protolith. (iii) If the microstructures formed after the majority of shearing-related deformation, we would expect no significant difference in CL microstructuresbetween protolith and sheared samples.

\subsubsection{Medium-dark grains}

Timing of formation of the medium-dark quartz grains can be constrained from the structural and metamorphic events at the sample locations and the relationship between luminescence and temperature. Medium-dark grains occur in or near the core of the Twelve Mile Bay shear zone (samples at D, Fig. 2) and the Parry Sound shear zone (GB21L), or near the site of inferred amphibolite-facies shearing (some samples at Matches Island, M, Fig. 2). There is evidence for younger shearing in the Twelve Mile Bay shear zone from both a few zircon dates (Marsh et al. 2012, 2013), and lower $\delta^{18} \mathrm{O}$ (Marsh et al. 2011). On Matches Island (which lies $\sim 5$ km outside of the Twelve Mile Bay shear zone core, M, Fig. 2), a local second shearing event is 
likely (Regan et al., 2014; Culshaw, personal communication). Similar reactivation at the nearby sites of B1-4A and GB90A is probable. FTIR results suggest that higher water content likely correlates with the medium-dark structure, consistent with amphibolite-facies hydration. Given the nature of the majority of settings that exhibit medium-dark grains, we interpret an origin by recrystallization during late-stage shearing. Because luminescence tends to correlate with temperature (e.g. Rusk et al. 2006), we suggest that the medium-dark grains formed during lower temperature amphibolite-facies conditions than the brighter cores elsewhere in the interior Parry Sound domain.

In addition, our data suggest that luminescence did not change appreciably across a range of high temperature $\left(850-650^{\circ} \mathrm{C}\right)$ conditions. Cores of quartz within pristine granulites luminesce at the same levels as the cores of grains formed during amphibolite-facies retrogression. Therefore, we suggest that quartz CL brightness remained the same from peak granulite-facies temperatures to the upper amphibolite-facies temperatures at which the meter-scale shear zones in the interior Parry Sound Domain formed. As the domain cooled to lower amphibolite-facies conditions, shearing continued in the kilometer-scale shear zones and localized areas within the Zone of Reworking causing quartz to recrystallize with a darker CL signature.

\subsubsection{Feldspar evolution - context for quartz mantles}

Feldspar grain morphology in the protolith contrasts sharply with that in the sheared rocks. Due to their presence within protolith samples throughout the Parry Sound domain interior, we interpret that the large antiperthitic grains ( $>2 \mathrm{~mm}$, Fig. 8a) formed at granulite or earlier conditions. Some protolith samples contain small plagioclase grains $(\sim 10-30 \mu \mathrm{m})$ mantling the large antiperthites (Fig. 8b). The progression from small grains in protolith samples to polygonal grain clusters (grain size $\sim 600 \mu \mathrm{m}$; Fig. $8 \mathrm{c}$ ) in sheared samples indicates that the 
plagioclase grains in shear zones underwent complete recrystallization and later grain growth. Because the grains in sheared samples are fairly polygonal and equant, we infer that they underwent a period of quasi-static grain boundary adjustment after the shearing event which ended by the time the rocks had cooled to $640^{\circ} \mathrm{C}$ (Marsh et al. 2013). Recrystallization in plagioclase generally requires temperatures $>400^{\circ} \mathrm{C}$ (Passchier and Trouw 2005), restricting the recrystallization temperature range to $\sim 400-710^{\circ} \mathrm{C}$.

Both relict and recrystallized plagioclase grains from "pristine" granulites, protolith, and sheared samples have wide, diffuse rims of brighter CL (Fig. 9) that are due to trace elements and/or defects. However, the rims are not present in all recrystallized grains, so we infer that the CL-bright rims formed during the last stages of grain boundary adjustment in recrystallized grains.

\subsubsection{Mantles}

Because no significant difference exists in either quartz mantle morphology or average mantle width between protolith and sheared samples (Table 3), the mantles likely formed after the recrystallization that resulted in the change in grain shape and orientation. Therefore, we consider that the calculated amphibolite-facies equilibration temperature $\left(640-710^{\circ} \mathrm{C}\right.$; Marsh et al. 2013) is the maximum temperature for mantle formation and thatthe lower luminescence in the mantles is primarily a function of a lower (re)crystallization temperature than experienced by the cores (cf. Rusk et al. 2006). This implies that some cooling must have taken place between the end of shearing-related recrystallization and the formation of the mantles.

CL-bright rims in plagioclase provide the lower temperature constraint on the formation of the quartz mantles. Because both the plagioclase rims and quartz mantles are due to trace element concentration variation, we infer that they formed synchronously. The plagioclase rims 
formed during static recrystallization after amphibolite-facies shearing ceased, possibly down to $\sim 400^{\circ} \mathrm{C}$. Therefore, the quartz mantles most likely formed after shearing, below $640-710^{\circ} \mathrm{C}$ and above $400^{\circ} \mathrm{C}$. Relict plagioclase grains also have some CL-bright rims that may have formed either during shearing or at the same time as the quartz mantles.

\subsubsection{Sinuous lines}

Sinuous lines are subgrain boundaries, and because the subgrains have very low-angle misorientations $\left(<3^{\circ}\right)$ and are irregularly shaped, they likely formed under low differential stress and low strain. There is no significant difference in character or abundance of sinuous CL lines between protolith and sheared sample pairs, so we interpret that the presently preserved subgrains formed after the amphibolite-facies shearing event. However, the evidence does not completely exclude the possibility of formation during meter-scale shearing followed by recovery. Subgrains can readily form at temperatures above $400^{\circ} \mathrm{C}$ for pressures and stresses typical of the Parry Sound domain (e.g. Kruhl 1996), and as noted, the lowest calculated amphibolite-facies equilibration temperature is $640-710^{\circ} \mathrm{C}$ (Marsh et al. 2013), so we deduce that the the sinuous lines formed in the temperature range of $710-400{ }^{\circ} \mathrm{C}$. We do not have sufficient evidence to determine the relative timing of sinuous line and mantle formation.

\subsubsection{Straight lines}

There is no noticeable difference in the character or abundance of straight lines between protolith and sheared samples, so they must have formed after the shearing event. Because quartz formed at lower temperatures tends to have lower luminescence (Rusk et al. 2006), the straight lines are consistent with fractures healing under conditions cooler than the original quartz crystallization temperature. Fluid inclusion planes commonly form with temperatures and pressures of entrapment at or below $400{ }^{\circ} \mathrm{C}$ and 2 kbar (e.g. Laubach 1989; Benko et al. 2014). 
Many other studies have reported CL dark lines and also interpreted them as relatively low temperature healed cracks (e.g. Muto et al. 2005; Vasyukova et al. 2013). Therefore, we infer that the straight lines formed at $<400{ }^{\circ} \mathrm{C}$, during exhumation.

\subsection{Summary of the evolution of the Parry Sound domain and the CL microstructures}

In this section we relate the development of the microstructures described herein to the tectonic history of the Parry Sound domain established by others (Figs. 13 and 14). Here we focus on the microstructural progression of felsic layers, although our interpretation also applies to the few other lithologies studied. Based on the trends noted in other studies (e.g., Rusk et al. 2006), we infer that CL intensity of quartz decreased with cooling temperatures consistent with a transition from bright, to medium-dark, to dark within the amphibolite facies (fig. 14). We therefore distinguish between events that took place under higher-temperature and lowertemperature amphibolite-facies conditions, which has not been done in previous studies.

Stage 1: At granulite-facies conditions, the felsic layers contain CL-bright quartz and antiperthitic plagioclase grains.

Stage 2: The domain cools to upper amphibolite-facies conditions, and during nappe transport and pegmatite intrusion, fluids infiltrate the wall rocks initiating meter-scale shearing (Culshaw et al. 2010; Marsh et al. 2011). Quartz domains in the shear zones change orientation and shape, and, although recrystallizing, maintain a bright CL character. Plagioclase in the shear zones undergoes recrystallization, grain size reduction, and compositional change (Marsh et al. 2011). Unsheared regions maintain their granulite mineralogy and most of their textures. At this point, quartz CL intensity is the same in both sheared and protolith rocks - bright with no dark microstructures. 
Stage 3: As the Parry Sound domain cools to relatively lower amphibolite-facies conditions, most of the shearing in the interior of the domain has ceased and strain is localized into the kilometer-scale shear zones (Twelve Mile Bay and Parry Sound shear zones). Where shearing has ceased, plagioclase anneals under low differential stress and forms equant, polygonal grains. The kilometer-scale shear zones are still deforming, with quartz recrystallizing under cooler conditions, forming the medium-dark grains.

Stage 4: After shearing ceases everywhere, likely under low amphibolite-facies temperatures, a small amount of residual water at the grain boundaries begins forming dark CL mantles in quartz and bright CL rims in plagioclase as they continue to anneal. Water acts on quartz in all regions throughout the domain - sheared amphibolite, 'pristine' granulite, and kilometer-scale shear zones.

Stage 5: Perhaps synchronous with Stage 4 , while still above $\sim 400^{\circ} \mathrm{C}$, sinuous lines (subgrains) form under low differential stress.

Stage 6: Lastly, once the domain has cooled below $\sim 400^{\circ} \mathrm{C}$, microcracking and healing forms the straight lines (fluid inclusion planes).

\subsection{Implications}

\subsubsection{Structural history}

Culshaw et al. (2010) and Marsh et al. (2011) have hypothesized that shearing in the Parry Sound domain initiated as meter-scale shear zones throughout the domain which then coalesced into more efficient kilometer-scale shear zones at the domain margins - a progressively narrowing shear system. The evidence for younger shearing in the Twelve Mile Bay shear zone comes from zircon ages from a few grains (Marsh et al. 2012, 2013) and lower $\delta^{18} \mathrm{O}$ (Marsh et al. 2011), which is consistent with but does not require the shear-narrowing hypothesis. The 
presence of the medium-dark grains provides additional support for the shear-narrowing hypothesis. Based on the relationship between CL intensity and temperature, we deduce that shearing ceased in most of the interior Parry Sound domain at higher temperatures (CL-bright cores) than rocks in and around the Twelve Mile Bay shear zone and a few other locations which contain medium-dark grains. We emphasize that CL microstructures are more easily evaluated in a greater number of samples than are zircon ages or $\delta^{18} \mathrm{O}$ analysis, and our data suggest that CL intensity is more sensitive to temperature changes than the uncertainties associated with many geothermometers, which is important because all shearing took place within a limited range of amphibolite-facies conditions. So in conclusion, we consider that the CL microstructures presented here not only support the shear-narrowing hypothesis, but also provide more robust information about the spatial distribution of late shearing.

\subsubsection{Postkinematic recrystallization}

Mantles provide previously unidentified evidence of postkinematic chemical processes, developing from small amounts of water present on grain boundaries after the amphibolite-facies shearing event. Because quartz from throughout the domain, even in areas far from shear zones, has mantles, this postkinematic alteration is widespread. This implies that rim compositions of minerals that morphologically do not appear affected after shearing may have in fact experienced postkinematic recrystallization.

\section{Conclusions}

We characterize and interpret four CL microstructures in quartz from the Parry Sound domain as follows: (1) Medium-dark grains formed as products of shear-related recrystallization under cooler amphibolite-facies conditions than grains that maintain bright CL signatures; (2) Dark mantles formed $>400^{\circ} \mathrm{C}$ by a water-facilitated mechanism after shearing had ceased; (3) 
Sinuous lines are subgrain boundaries formed $>400^{\circ} \mathrm{C}$ by subgrain rotation recrystallization after major shearing had ceased; and (4) Straight lines are fluid inclusion planes and thus healed or sealed fractures formed at low temperatures $\left(<400^{\circ} \mathrm{C}\right)$ during exhumation

Whereas fluid inclusion planes (straight lines) and subgrains (sinuous lines) are widely recognized in this type of geological setting and do not provide new insight into deeper crustal processes, the dark mantles and medium-dark grains provide new information about the highgrade history of the domain that may apply to other orogenic rocks. Because the mantles reflect postkinematic alteration, they indicate the presence of fluids and grain boundary compositional changes following the cessation of deformation, with potential implications for interpreting mineral chemistry analyses. Separately, medium-dark grains provide further support to the hypothesis that the margins of the Parry Sound domain represent a shear-narrowing system at the kilometer scale.

\section{Acknowledgements}

NSF awards EAR-0820946 and 1150438 to CG supported this project, along with funds from the UMaine Graduate Student Government (to SGM). Liam Kenefic assisted with image analysis and Michael Jercinovic with CL spectroscopy. We appreciate valuable conversations with too many people to list, but we would especially like to acknowledge Scott Johnson, Nick Culshaw, Peter Regan, Jay Thomas, and Frank Spear. We thank Toby Rivers and two anonymous reviewers for improving the clarity of the manuscript and Ali Polat for his editorial assistance.

\section{References}

Ashley, K.T., Webb, L.E., Spear, F.S., and Thomas, J.B. 2013. P-T-D histories from quartz: A 
case study of the application of the TitaniQ thermobarometer to progressive fabric development in metapelites. Geochemistry Geophysics Geosystems, 14:3821-3843. doi: 10.1002/ggge.20237.

Benkó, Z., Molnár, F., Lespinasse, M., and Váczi, T. 2014. Evidence for exhumation of a granite intrusion in a regional extensional stress regime based on coupled microstructural and fluid inclusion plane studies - An example from the Velence Mts., Hungary. J Structural Geology, 65:44-58. doi: 10.1016/j.jsg.2014.04.001.

Bergman, H., and Piazolo, S. 2012. The recognition of multiple magmatic events and preexisting deformation zones in metamorphic rocks as illustrated by CL signatures and numerical modelling: Examples from the Ballachulish contact aureole, Scotland. International Journal of Earth Sciences, 101:1127-1148. doi: 10.1007/s00531-011-0731-6.

Bestmann, M., Pennacchioni, G., Mostefaoui, S., Göken, M., and de Wall, H. 2016. Instantaneous healing of micro-fractures during coseismic slip: Evidence from microstructure and $\mathrm{Ti}$ in quartz geochemistry within an exhumed pseudotachylyte-bearing fault in tonalite. Lithos, 254-255:84-93.

Blenkinsop, T.G., and Drury, M.R. 1988. Stress estimates and fault history from quartz microstructures. Journal of Structural Geology, 10:673-684. doi: 10.1016/01918141(88)90075-2.

Boggs, S., Jr., and Krinsley, D. 2006. Applications of cathodoluminescence imaging to the study of sedimentary rocks. Cambridge University Press, Cambridge.

Brace, W.F., and Kohlstedt, D.L. 1980. Limits on lithospheric stress imposed by laboratory experiments. Journal of Geophysical Research, 85:6248. doi: 10.1029/JB085iB11p06248.

Bufe, N.A., Holness, M.B., and Humphreys, M.C.S. 2014. Contact metamorphism of 
Precambrian gneiss by the Skaergaard intrusion. Journal of Petrology, 55:1595-1617. doi: 10.1093/petrology/egu035.

Carr, S.D., Easton, R.M., Jamieson, R.A., and Culshaw, N.G. 2000. Geologic transect across the Grenville orogen of Ontario and New York. Canadian Journal of Earth Sciences, 37:193216. doi: 10.1139/e99-074.

Culshaw, N.G., Check, G., Corrigan, D., Drage, J., Gower, R., Haggart, M.J., Wallace, P., and Wodicka, N. 1989. Georgian Bay geological synthesis: Dillon to Twelve Mile Bay, Grenville Province of Ontario: Current Research, Part C. Geological Survey of Canada, 891C:157-163.

Culshaw, N.G., Jamieson, R.A., Ketchum, J.W.F., Wodicka, N., Corrigan, D., Reynolds, P.H. 1997. Transect across the northwestern Grenville orogen, Georgian Bay, Ontario: Polystage convergence and extension in the lower orogenic crust. Tectonics, 16:966-982.

Culshaw, N., Corrigan, D., Ketchum, J., Wallace, P., Wodicka, N., and Easton, R.M. 2004. Georgian Bay geological synthesis, Grenville Province: Explanatory notes for Preliminary Maps P.3548 to P3552; Ontario Geological Survey, Open File Report. Ontario Geological Survey $1-49$.

Culshaw, N., Gerbi, C., and Marsh, J. 2010. Softening the lower crust: Modes of syn-transport transposition around and adjacent to a deep crustal granulite nappe, Parry Sound domain, Grenville Province, Ontario, Canada. Tectonics, 29:TC5013. doi: 10.1029/2009TC002537. Culshaw, N., Gerbi, C., Marsh, J., and Plug, L. 2011. Heterogeneous amphibolite facies deformation of a granulite facies layered protolith: Matches Island shear system, Parry Sound domain, Grenville Province, Ontario, Canada. Journal of Structural Geology, 33:875-890. doi: 10.1016/j.jsg.2011.03.005. 
Davidson, A. 1984. Tectonic boundaries within the Grenville Province of the Canadian shield. Journal of Geodynamics 1:433-444

Davidson, A., Nadeau, L., Grant, S.M., and Pryer, L.L. 1985. Studies in the Grenville Province of Ontario. In: Current Research, Part A. Geological Survey Canada, 85-1A:463-483.

Den Brok, B., Zahid, M., and Passchier, C. 1998. Cataclastic solution creep of very soluble brittle salt as a rock analogue. Earth and Planetary Science Letters, 163:83-95.

Gerbi, C., Culshaw, N., and Marsh, J. 2010. Magnitude of weakening during crustal-scale shear zone development. Journal of Structural Geology, 32:107-117. doi:

10.1016/j.jsg.2009.10.002.

Götze, J. 2009. Chemistry, textures and physical properties of quartz - geological interpretation and technical application. Mineralogical Magazine, 73:645-671.

Götze, J., Plötze, M., and Habermann, D. 2001. Origin, spectral characteristics and practical applications of the cathodoluminescence (CL) of quartz - A review. Mineralogy and Petrology, 71:225-250. doi: 10.1007/s007100170040.

Hamers, M.F., Pennock, G.M., Drury, M.R. (in press). Scanning electron microscope cathodoluminescence imaging of subgrain boundaries, twins and planar deformation features in quartz. Physics and Chemistry of Minerals. doi: 10.1007/s00269-016-0858-x.

Handy, M.R. 1990. The solid-state flow of polymineralic rocks. Journal of Geophysical Research, 95:8647-8661. doi: 10.1029/JB095iB06p08647.

Handy, M.R., Hirth, G., and Bürgmann, R. 2007. Continental fault structure and rheology from the frictional-to-viscous transition downward. In: Handy, M.R., Hirth, G., and Hovius N (Editors) Tectonic Faults: Agents of Change on a Dynamic Earth. MIT Press, Cambridge, MA, pp. 139-181. 
Harris, N., McMillan, A., Holness, M., Uken, R., Watkeys, M., Rogers, N., and Fallick, A. 2003. Melt generation and fluid flow in the thermal aureole of the bushveld complex. Journal of Petrology, 44:1031-1054. doi: 10.1093/petrology/44.6.1031.

Hirth, G., and Tullins, J. 1992. Dislocation creep regimes in quartz aggregates. Journal of Structural Geology, 14:145-159.

Holness, M.B., and Watt, G.R. 2001. Quartz recrystallization and fluid flow during contact metamorphism: a cathodoluinescence study. Geofluids, 1:215-228.

Kearey, P., Klepeis, K.A., and Vine, F.J. 2009. Global Tectonics, third edition. Wiley-Blackwell, West Sussex, UK.

Kilian, R., Heilbronner, R., and Stünitz, H. 2011. Quartz grain size reduction in a granitoid rock and the transition from dislocation to diffusion creep. Journal of Structural Geology, 33:1265-1284. doi: 10.1016/j.jsg.2011.05.004.

Koons, P.O., Zeitler, P.K., and Hallet, B. 2012. Tectonic aneurysms and mountain building. In: Treatise on Geomorphology 5.19. doi: 10.1016/B978-0-12-374739-6.00094-4.

Kruhl, J.H. 1996. Prism- and basal-plane parallel subgrain boundaries in quartz: a microstructural geothermobarometer. Journal of Metamorphic Geology, 14:581-589.

Lambrecht, G., and Diamond, L.W. 2014. Morphological ripening of fluid inclusions and coupled zone-refining in quartz crystals revealed by cathodoluminescence imaging: Implications for CL-petrography, fluid inclusion analysis and trace-element geothermometry. Geochimica et Cosmochimica Acta, 141:381-406. doi: 10.1016/j.gca.2014.06.036.

Laubach, S.E. 1989. Paleostress directions from the preferred orientation of closed microfractures (fluid-inclusion planes) in sandstone, East Texas basin, U.S.A. J Struct Geol 
11:603-611. doi: 10.1016/0191-8141(89)90091-6.

Libowitzky, E., and Rossman, G.R. 1996. Principles of quantitative absorbance measurements in anisotropic crystals. Physics and Chemistry of Minerals, 23:319-327.

Libowitzky, E., and Rossman, G.R. 1997. An IR absorption calibration for water in minerals. American Mineralogist, 82:1111-1115.

Mainprice, D., Bouchez, J.L., Blumenfeld, P., and Tubià, J.M. 1986. Dominant c slip in naturally deformed quartz: Implications for dramatic plastic softening at high temperature. Geology 14:819-822. doi: 10.1130/0091-7613(1986)14<819:DCSIND>2.0.CO;2.

Marsh, J.H., Gerbi, C.C., Culshaw, N.G., Potter, J., Longstaffe, F.J., and Johnson, S.E. 2011. Initiation and development of the Twelve Mile Bay shear zone: The low viscosity sole of a granulite nappe. Journal of Metamorphic Geology, 29:167-191. doi: 10.1111/j.15251314.2010.00913.x.

Marsh, J.H., Gerbi, C.C., Culshaw, N.G., Johnson, S.E., Wooden, J.L., and Clark, C. 2012. Using zircon $\mathrm{U}-\mathrm{Pb}$ ages and trace element chemistry to constrain the timing of metamorphic events, pegmatite dike emplacement, and shearing in the southern Parry Sound domain, Grenville Province, Canada. Precambrian Research, 192-195:142-165. doi: 10.1016/j.precamres.2011.10.017.

Marsh, J.H., Culshaw, N.G., and Gerbi, C.C. 2013. Timing and conditions of poly-phase metamorphism within the Twelve Mile Bay shear zone: implications for the evolution of mid-crustal decollement zones and western Grenville tectonics. International Geology Reviews, 55:525-547. doi: 10.1080/00206814.2013.773768.

Mills, S.G. 2015. Cathodoluminescent quartz microstructure: Their formation and role in high grade rocks of the Parry Sound domain, Grenville Province, Ontario, Canada. M.Sc. thesis, 
School of Earth and Climate Science, University of Maine, Orono, ME.

Muto, J., Nagahama, H., and Hashimoto, T. 2005. Water distribution in dynamically recrystallized quartz grains: cathodoluminescence and micro-infrared spectroscopic mapping. Geological Society of London, Special Publications 245:397-407. doi: 10.1144/GSL.SP.2005.245.01.19.

Passchier, C.W., and Trouw, R.A. 2005. Microtectonics. Springer-Verlag, Berlin.

Regan, P., Culshaw, N.G., and Gerbi, C. 2014. Transposition of a layered granulite by the progressive development of amphibolite facies shear zones, Twelve Mile Bay, Ontario: Techniques and results. In: Geological Association of Canada - Mineralogical Association of Canada Joint Annual Meeting Abstracts, 37:230.

Rivers, T. 2012. Upper-crustal orogenic lid and mid-crustal core complexes: signature of a collapsed orogenic plateau in the hinterland of the Grenville Province. Canadian Journal of Earth Sciences, 49:1-42.

Rossetti, F., Tecce, F., Aldega, L., Brilli, M., and Faccenna, C. 2006. Deformation and fluid flow during orogeny at the palaeo-Pacific active margin of Gondwana: The Early Palaeozoic Robertson Bay accretionary complex (north Victoria Land, Antarctica). Journal of Metamorphic Geololgy, 24:33-53. doi: 10.1111/j.1525-1314.2005.00620.x.

Rusk, B.G., Reed, M.H., Dilles, J.H., Kent, A.J.R. 2006. Intensity of quartz cathodoluminescence and trace-element content in quartz from the porphyry copper deposit at Butte, Montana. American Mineralogist, 91:1300-1312. doi: 10.2138/am.2006.1984.

Rusk, B.G., Lowers, H.A., Reed, M.H. 2008. Trace elements in hydrothermal quartz: Relationships to cathodoluminescent textures and insights into vein formation. Geology, 36:547-550. doi: 10.1130/G24580A.1. 
Spear, F.S., and Wark, D.A. 2009. Cathodoluminescence imaging and titanium thermometry in metamorphic quartz. Journal of Metamorphic Geology, 27:187-205. doi: 10.1111/j.15251314.2009.00813.x.

Spear, F.S., Ashley, K.T., Webb, L.E., and Thomas, J.B. 2012. Ti diffusion in quartz inclusions: implications for metamorphic time scales. Contributions to Mineralogy and Petrology, 164:977-986. doi: 10.1007/s00410-012-0783-z.

Stipp, M., Tullis, J., and Behrens, H. 2006. Effect of water on the dislocation creep microstructure and flow stress of quartz and implications for the recrystallized grain size piezometer. Journal of Geophysical Research Solid Earth, 111:B04201. doi: 10.1029/2005JB003852.

Storm, L.C., and Spear, F.S. 2009. Application of the titanium-in-quartz thermometer to pelitic migmatites from the Adirondack Highlands, New York. Journal of Metamorphic Geology, 27:479-494. doi: 10.1111/j.1525-1314.2009.00829.x.

Thompson, D.L. 1983. The nature of anorthosite-country rock interaction during granulite facies metamorphism. M.Sc. thesis, McMaster University, Hamilton, Ontario.

Tuttle, O.F. 1949. Structural petrology of planes of liquid inclusions. The Journal of Geology, $57: 331-356$.

van Breemen, O., and Hanmer, S.K. 1986. Zircon morphology and the U/Pb geochronology in active shear zones: studies on syntectonic intrusions along the northwest boundary of the Central Metasedimentary Belt, Grenville Province, Ontario. Geological Survey of Canada Paper, 86-1B:775-785

van Breemen, O., Davidson, A., Loveridge, W.D., and Sullivan, R.W. 1986. U-Pb zircon geochronology of Grenville tectonites, granulites and igneous precursors, Parry Sound, 
Ontario. The Grenville Province. Geological Association of Canada Special Paper, 31:191207.

van den Kerkhof, A.M., Kronz, A., Simon, K., and Scherer, T. 2004. Fluid-controlled quartz recovery in granulite as revealed by cathodoluminescence and trace element analysis (Bamble sector, Norway). Contributions to Mineralogy and Petrology, 146:637-652. doi: 10.1007/s00410-003-0523-5.

Vasyukova, O.V., Goemann, K., Kamenetsky, V.S., MacRae, C.M., and Wilson, N.C. 2013. Cathodoluminescence properties of quartz eyes from porphyry-type deposits: Implications for the origin of quartz. American Mineralogist, 98:98-109. doi: 10.2138/am.2013.4018.

Wark, D.A., and Watson, E.B. 2006. TitaniQ: A titanium-in-quartz geothermometer. Contributions to Mineralogy and Petrology 152:743-754. doi: 10.1007/s00410-006-0132-1. Watt, G.R., Oliver, N.H.S., and Griffin, B.J. 2000. Evidence for reaction-induced microfracturing in granulite facies migmatites. Geology, 28:327-330. doi: 10.1130/00917613(2000)28<327:EFRMIG>2.0.CO.

Wodicka, N., Parrish, R.R., and Jamieson, R.A. 1996. The Parry Sound domain: a far-travelled allochthon? New evidence from U-Pb zircon geochronology. Canadian Journal of Earth Sciences, 33:1087-1104.

Wodicka, N., Ketchum, J.W.F., and Jamieson, R.A. 2000. Grenvillian metamorphism of monocyclic rocks, Georgian Bay, Ontario, Canada: Implications for convergence history. Canadian Mineralogist, 38:471-510. doi: DOI 10.2113/gscanmin.38.2.471. 
Tables

Table 1. Sample,location, and microstructures.

\begin{tabular}{|c|c|c|c|c|c|c|}
\hline Location ID & Easting & $\begin{array}{l}\text { North- } \\
\text { ing }\end{array}$ & $\begin{array}{l}\text { Protolith } \\
\text { (sample name } \\
\text { if part of pair) }\end{array}$ & $\begin{array}{l}\text { Sheared } \\
\text { (sample } \\
\text { name if } \\
\text { part of } \\
\text { pair) }\end{array}$ & $\begin{array}{l}\text { Geological } \\
\text { setting } \\
\text { details }\end{array}$ & $\begin{array}{l}\text { CL Micro- } \\
\text { structures }^{\text {a }}\end{array}$ \\
\hline B1-4A & 0567531 & 5003719 & Yes & & Granulite & $\begin{array}{l}\text { md, ma, si, } \\
\text { st }\end{array}$ \\
\hline GB21L & 577734 & 5022719 & Yes & & $\begin{array}{l}\text { High-strain } \\
\text { granulite }^{\mathrm{b}}\end{array}$ & $\begin{array}{l}\text { md, ma, si, } \\
\text { st }\end{array}$ \\
\hline GB38 & 567503 & 4999370 & $\mathrm{~A}$ & B & $\begin{array}{l}\text { Pair from the } \\
\text { same layer }\end{array}$ & $\mathrm{md}, \mathrm{si}^{\mathrm{c}}, \mathrm{st}^{\mathrm{c}}$ \\
\hline GB50D & 570140 & 4995099 & & Yes & $\begin{array}{l}\text { In km-scale } \\
\text { shear zone }\end{array}$ & md \\
\hline GB50H & 570140 & 4995099 & & Yes & $\begin{array}{l}\text { In km-scale } \\
\text { shear zone }\end{array}$ & md \\
\hline GB55,56,58 & 0568111 & 4995948 & 55,56 & 58 & $\begin{array}{l}\text { Set from the } \\
\text { same layer }\end{array}$ & ma, si, st \\
\hline GB61 & 567469 & 5001572 & $\mathrm{~A}, \mathrm{AN} 1, \mathrm{~F}, \mathrm{G}$ & $\mathrm{I}, \mathrm{J}, \mathrm{K}$ & & ma, si, st \\
\hline GB6 & 567539 & 4999439 & & $\mathrm{E}$ & $\begin{array}{l}\text { Pair from } \\
\text { the same } \\
\text { layer }\end{array}$ & md \\
\hline GB8 & 567498 & 4999360 & $\mathrm{C}$ & A & $\begin{array}{l}\text { Pair from } \\
\text { the same } \\
\text { layer }\end{array}$ & ma, si, st \\
\hline GB83C & 569619 & 5007184 & & & $\begin{array}{l}\text { Pristine } \\
\text { granulite }\end{array}$ & \\
\hline GB9C & 558747 & 5015969 & & Yes & Quartzite & ma, si, st \\
\hline GB90A & 566777 & 5200102 & Yes & & $\begin{array}{l}\text { Granulite } \\
\text { assemblage, } \\
\text { adjacent to } \\
\text { retrogressed } \\
\text { areas }\end{array}$ & $\begin{array}{l}\text { md, ma, si, } \\
\text { st }\end{array}$ \\
\hline
\end{tabular}

${ }^{\mathrm{a}}$ Abbreviations: $\mathrm{md}=$ medium-dark grains, $\mathrm{ma}=$ mantles, $\mathrm{si}=$ sinuous lines, $\mathrm{st}=$ straight lines.

All samples that are not marked "md" have bright cores.

${ }^{b}$ Texturally, this sample is a part of a granulite area, however the mineralogy of the sample itself does not allow determination of mineral facies. The sample is from near an amphibolite facies, 
meter-scale shear zone.

${ }^{\mathrm{c}}$ These are only visible in sample A from this pair in a few large grains that maintain a bright core. These grains have large, diffuse mantles that we interpret as the beginning stage of the formation of full medium-dark grains.

Table 2. Ti and Fe concentrations in quartz from GB61G determined by wavelength-dispersive EPMA.

\begin{tabular}{llll}
\hline & Core & Mantle & Detection limits \\
\hline Ti & $<22 \mathrm{ppm}$ & $<22 \mathrm{ppm}$ & $\sim 50-150 \mathrm{ppm}$ \\
Fe & $20-60 \mathrm{ppm}$ & $60-160 \mathrm{ppm}$ & $19-54 \mathrm{ppm}$ \\
\hline
\end{tabular}

Table 3. Effective average mantle width measured from CL images.

\begin{tabular}{|c|c|c|}
\hline Sample set & $\begin{array}{l}\text { Mantle width in protolith } \\
(\mu \mathrm{m})\end{array}$ & $\begin{array}{l}\text { Mantle width in sheared } \\
\text { rocks }(\mu \mathrm{m})\end{array}$ \\
\hline $8 \mathrm{C} / 8 \mathrm{~A}$ & 120 & 93 \\
\hline $55 / 58$ & 112 & 120 \\
\hline
\end{tabular}


Table 4.

Other techniques used to analyze microstructures observed in CL.

\begin{tabular}{lllll}
\hline $\begin{array}{l}\text { CL } \\
\text { Microstructure }\end{array}$ & $\begin{array}{l}\text { Medium-dark } \\
\text { grains }\end{array}$ & Mantles & Sinuous Lines & Straight Lines \\
\hline $\begin{array}{l}\text { Observable } \\
\text { with additional } \\
\text { technique }\end{array}$ & $\begin{array}{l}\text { FTIR of small } \\
\text { areas }\end{array}$ & EPMA & $\begin{array}{l}\text { some visible } \\
\text { optically }\end{array}$ & Optical \\
& & & $\begin{array}{l}\text { electron } \\
\text { backscatter } \\
\text { diffraction }\end{array}$ & \\
& & & FTIR \\
& & STEM & \\
\hline
\end{tabular}




\section{Figure Captions}

Fig. 1. Three CL-dark microstructures in quartz from the study area: sinuous lines, straight lines, and dark mantles. Dashed lines indicate grain boundaries. From sample GB61G (see Fig. 2).

Fig. 2. Map of the study area with sample locations (after Culshaw et al., 2010). (a) The Grenville Province in eastern North America; (b) Domains of the Central Gneiss Belt within and adjacent to the study area; (c) Geological map of the southwestern Parry Sound domain and adjacent domains. Parry Sound domain (PSD): bPSD = basal, iPSD = interior, $\mathrm{ZoR}=$ zone of reworking after Marsh et al. (2011), tp = transposed gneiss derived from Parry sound domain after Culshaw et al. (2010); thin dashed line marks the boundary between tp and ZoR after Marsh et al. (2011) and Culshaw et al. (2010). 1PSSZ - lithological boundary within lower strand of Parry Sound shear zone. uPSSZ - structural boundary at upper margin of upper strand of Parry Sound shear zone. TMBSZ - Twelve Mile Bay shear zone. Shear zones are mapped as structural and/or lithological boundaries, but their associated strain gradients extend throughout gray zones. The bPSD and part of the Twelve Mile Bay shear zone may be equivalent (cf. Marsh et al. 2013). Sample names listed with bold type in the key contain medium-dark grains. Note that all samples with bright cores contain mantles, sinuous lines, and straight lines.

Fig. 3. Protolith and sheared sample relationships on several scales. (a) Meter-scale: mafic and felsic layers in the protolith bend into shear zone; field of view is $\sim 1$ meter. (b) Centimeter-scale: Traces of quartz aggregates from a protolith — shear pair from the same felsic layer (GB55 and GB58) and a cartoon demonstrating the inferred grain shape and orientation changes during shearing. Foliation of the sheared sample is approximately orthogonal to protolith foliation, so grains were both rotated and stretched during shearing. (c) and (d) Micrometer-scale: CL images from samples in the same felsic layer; these samples are oriented with their foliations parallel 
rather than in field-orientation in order for easier comparison of mantle width and morphology. Mantles have similar morphology in (c) protolith (GB55) and (d) sheared samples (GB58). Mantle-core boundaries are outlined with white dashed lines. Mineral abbreviations after Whitney and Evans (2010).

Fig. 4. Quartz aggregate surrounded by plagioclase matrix. Plane polarized light. Solid line indicates boundary of quartz aggregate. Mineral abbreviations after Whitney and Evans (2010) Fig. 5. CL image of medium-dark quartz grains (GB21L; Parry Sound shear zone). Brightness and contrast have been adjusted so that mantles, straight lines and sinuous lines are visible. Bright grains are plagioclase and K-feldspar.

Fig. 6. CL-dark, intragranular patches (arrow) cored by darker lines which are fluid inclusions. These patches have an irregular shape and a radius of $\sim 50-200 \mu \mathrm{m}$ from the dark line, both similar properties to the mantles. Mineral abbreviations after Whitney and Evans (2010). Fig. 7. Typical, irregular quartz subgrain morphology of sample GB61J. (a) Cross-polarized light image; dashed line outlines one subgrain and arrows point to sinuous lines in (b). (b) CL image of the same area in (a); arrows point to some examples of sinuous lines that correspond to subgrain boundaries in (a). The brighter patch on the left is an artifact of imaging.

Fig. 8. CL images of feldspar textures. Vertical and horizontal lines are an artifact of scanning and stitching several images together. (a) Sample GB61G, large antiperthitic grains in protolith; (b) Sample GB55, large antiperthitic grains surrounded by small, brighter CL, equant, polygonal plagioclase in protolith. (c) Sample GB61J medium sized, equant, polygonal plagioclase in sheared sample. Mineral abbreviations after Whitney and Evans (2010).

Fig. 9. Recrystallized plagioclase (GB61J) viewed in CL with brightness and contrast adjusted to enhance internal features. Despite the field-wide CL intensity gradient, plagioclase rims are 
visibly brighter than the core.

Fig. 10. (a) CL image of straight lines and (b) optical image of fluid inclusion planes at the same locations. Arrows point to the same planes/lines. Dashed line, black in (a) and white in (b), indicates grain boundary. (c) Close-up of fluid inclusions; inset from (a). Mineral abbreviations after Whitney and Evans (2010).

Fig. 11. (a) CL image of area chosen for STEM foil from GB9C. Entire field of view is quartz. Arrow points to many tightly interconnected sinuous lines that are possibly the area imaged in (b). Due to standard STEM sample preparation and handling, it is difficult to know the exact location of (b) on (a). Some mantles are marked, but again we cannot be sure which images incorporated mantle area. (b) Solid lines trace subgrain boundaries that were directly imaged with STEM. Dashed lines indicate regions that were not imaged, so the boundaries are inferred. Imaged subgrain boundaries are the typical regular arrays of dislocations as seen in the representative STEM image.

Fig. 12. Area analyzed for water species concentration in quartz. Each panel shows the same area from GB38A. (a) Annotated CL image discriminating among morphological regions of analyzed area. Areas marked "medium-dark" and "core" are quartz with the light line as the boundary between the microstructures and the black line as the grain boundary. (b) Plane polarized light image showing areas that are contaminated. This section is $\sim 160 \mu \mathrm{m}$ thick, so grain boundaries at an angle appear wide in two dimensions. (c) FTIR map of water species concentration. The scale is only accurate for quartz because a different calibration is required for other minerals. Solid, thick outlines in core and medium-dark areas are of "uncontaminated" intragranular regions free from fractures, fluid inclusions, and portions of adjacent non-quartz minerals.

Fig. 13. Schematic illustration of microstructural evolution. Dark grey $=$ quartz, medium grey $=$ 
relict, antiperthitic plagioclase, light grey $=$ recrystallized plagioclase, black $=$ quartz CL microstructures. All are at the same scale. Stage 1: At granulite facies conditions, felsic layers contain CL-bright quartz and antiperthitic plagioclase grains. Stage 2: After cooling to upper amphibolite facies conditions, quartz domains in the shear zones change orientation and shape yet maintain a bright CL character. Plagioclase recrystallizes to a different grain size and composition. Stage 3: After cooling to lower-amphibolite facies conditions. Where shearing has ceased (left panel), quartz maintains bright CL cores and plagioclase grows to equant, polygonal grains. Where shearing persists (right panel), quartz recrystallizes to medium-dark grains. Stage 4: After shearing ceases everywhere, residual water at the grain boundaries forms dark CL mantles in quartz and bright CL rims in plagioclase. Stage 5: Above $\sim 400^{\circ} \mathrm{C}$, sinuous lines (subgrains) form under small amounts of differential stress and low strain. Stage 6: Below $\sim 400^{\circ} \mathrm{C}$, microcracking and healing forms the straight lines (fluid inclusion planes).

Fig. 14. Pressure-temperature-time path (after Marsh et al., 2013) with quartz CL microstructural events overlain. The CL intensity of the microstructures (grayscale background) reflects the temperature of recrystallization. 


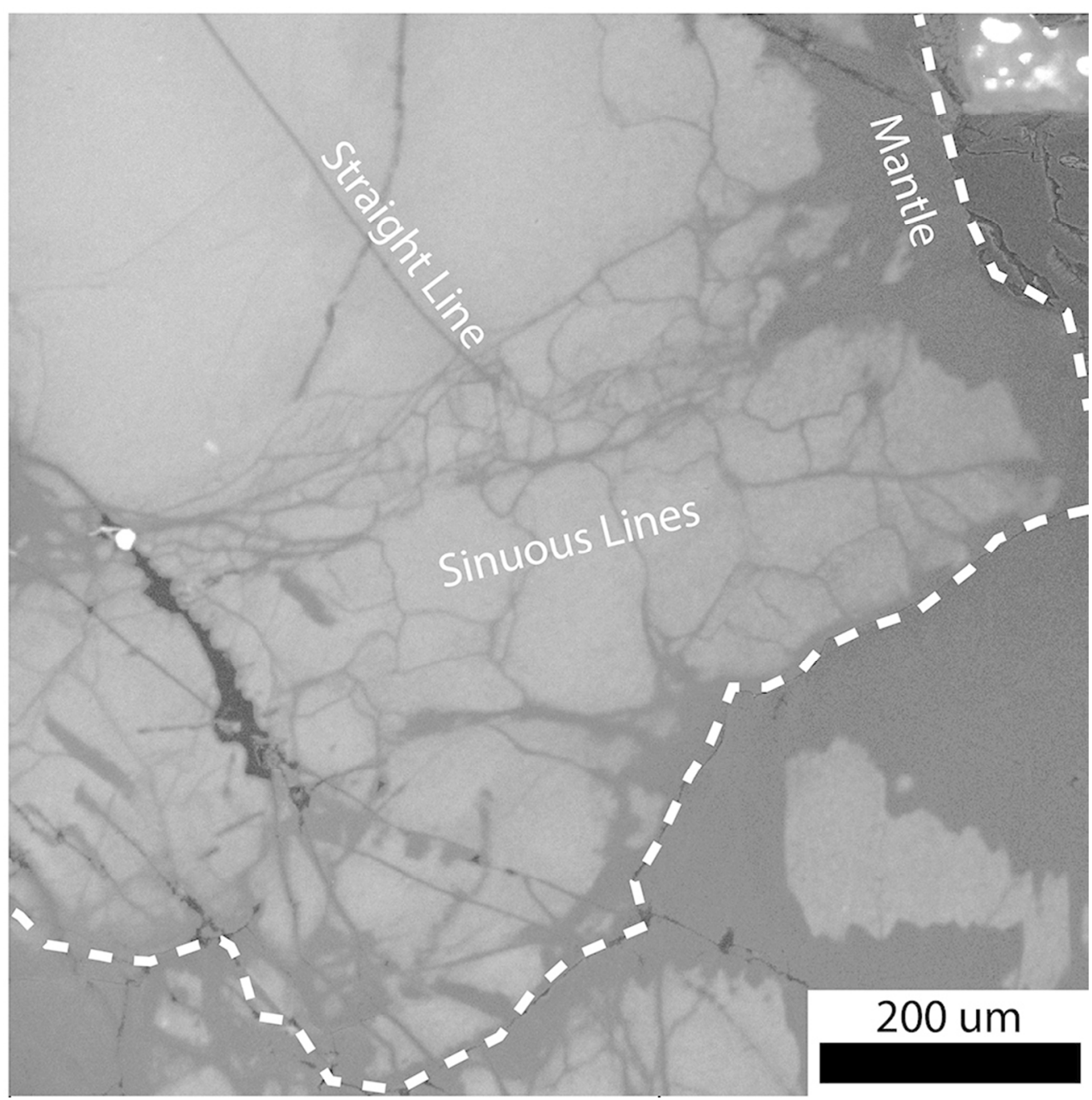

Fig. 1. Three CL-dark microstructures in quartz from the study area: sinuous lines, straight lines, and dark mantles. Dashed lines indicate grain boundaries. From sample GB61G (see Fig. 2).

$86 \times 86 \mathrm{~mm}(300 \times 300 \mathrm{DPI})$ 


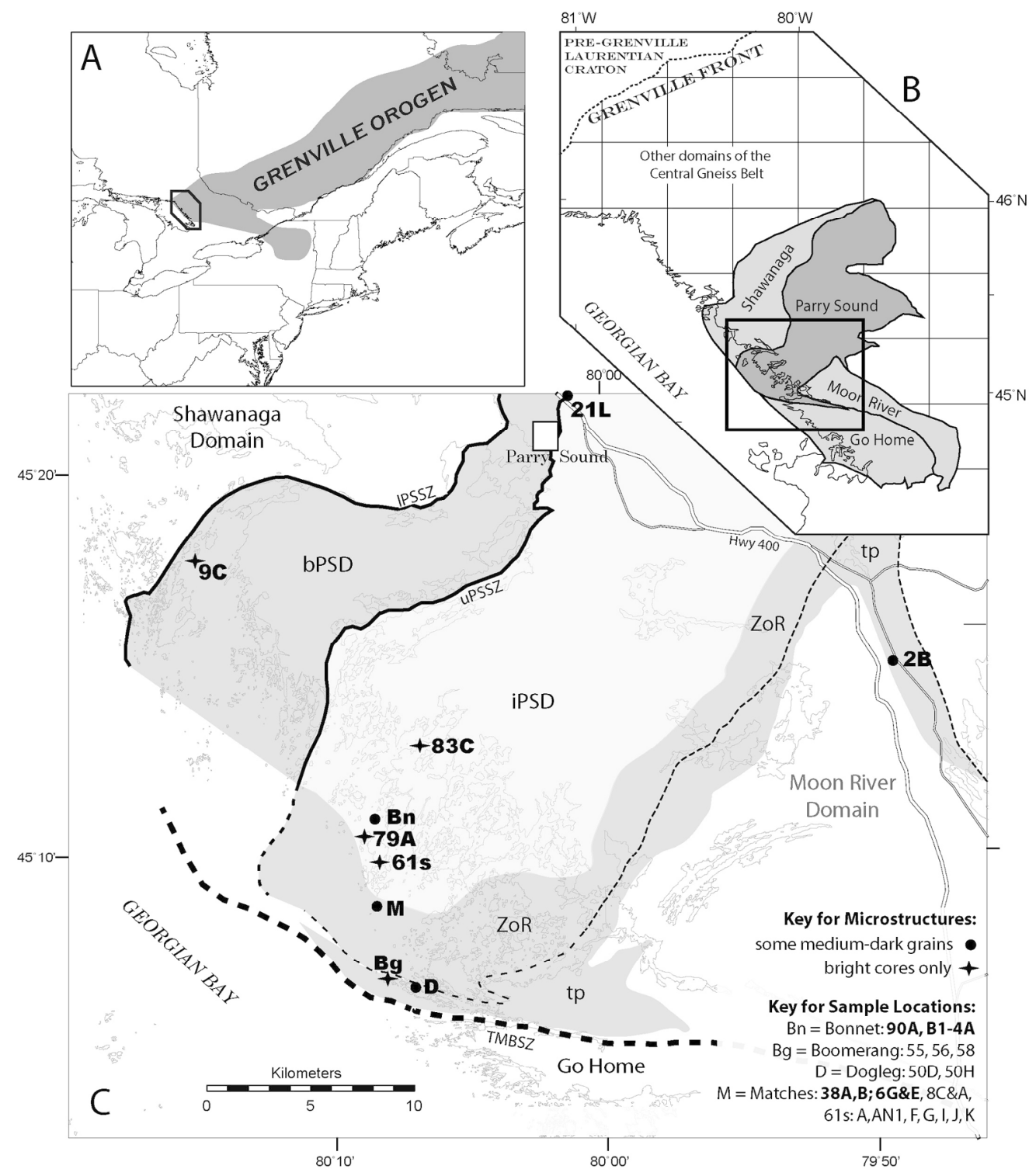

Fig. 2. Map of the study area with sample locations (after Culshaw et al., 2010). (a) The Grenville Province in eastern North America; (b) Domains of the Central Gneiss Belt within and adjacent to the study area; (c) Geological map of the southwestern Parry Sound domain and adjacent domains. Parry Sound domain (PSD): bPSD $=$ basal, iPSD = interior, ZoR = zone of reworking after Marsh et al. (2011), tp = transposed gneiss derived from Parry sound domain after Culshaw et al. (2010); thin dashed line marks the boundary between tp and ZoR after Marsh et al. (2011) and Culshaw et al. (2010). IPSSZ - lithological boundary within lower strand of Parry Sound shear zone. UPSSZ - structural boundary at upper margin of upper strand of Parry

Sound shear zone. TMBSZ - Twelve Mile Bay shear zone. Shear zones are mapped as structural and/or lithological boundaries, but their associated strain gradients extend throughout gray zones. The bPSD and part of the Twelve Mile Bay shear zone may be equivalent (cf. Marsh et al. 2013). Sample names listed with bold type in the key contain medium-dark grains. Note that all samples with bright cores contain mantles, sinuous lines, and straight lines. 


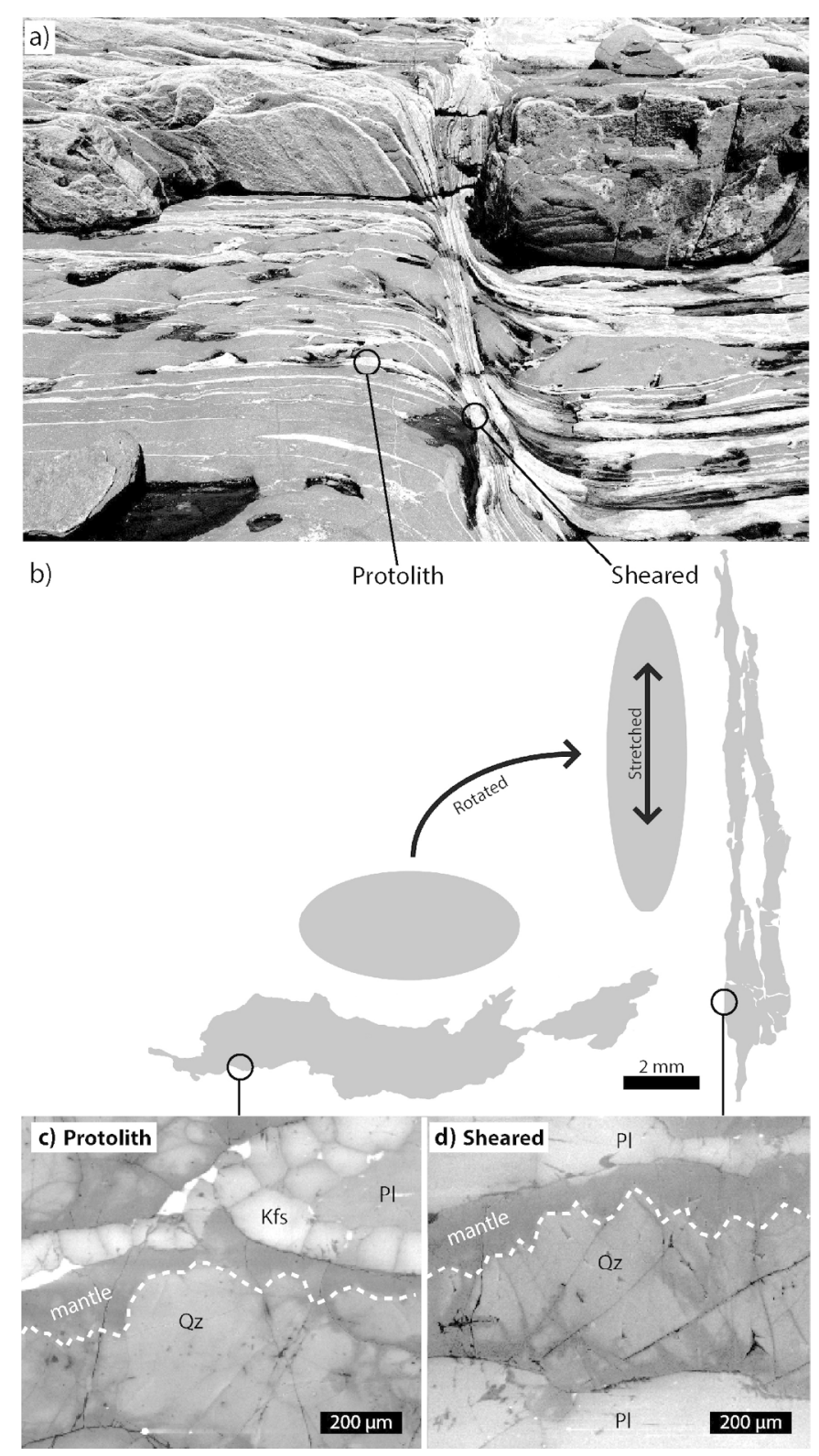

Fig. 3. Protolith and sheared sample relationships on several scales. (a) Meter-scale: mafic and felsic layers in the protolith bend into shear zone; field of view is $\sim 1$ meter. (b) Centimeter-scale: Traces of quartz aggregates from a protolith-shear pair from the same felsic layer (GB55 and GB58) and a cartoon demonstrating the inferred grain shape and orientation changes during shearing. Foliation of the sheared sample is approximately orthogonal to protolith foliation, so grains were both rotated and stretched during shearing. (c) and (d) Micrometer-scale: CL images from samples in the same felsic layer; these samples are oriented with their foliations parallel rather than in field-orientation in order for easier comparison of mantle width and morphology. Mantles have similar morphology in (c) protolith (GB55) and (d) sheared samples (GB58). Mantle-core boundaries are outlined with white dashed lines. Mineral abbreviations after Whitney and Evans (2010). 


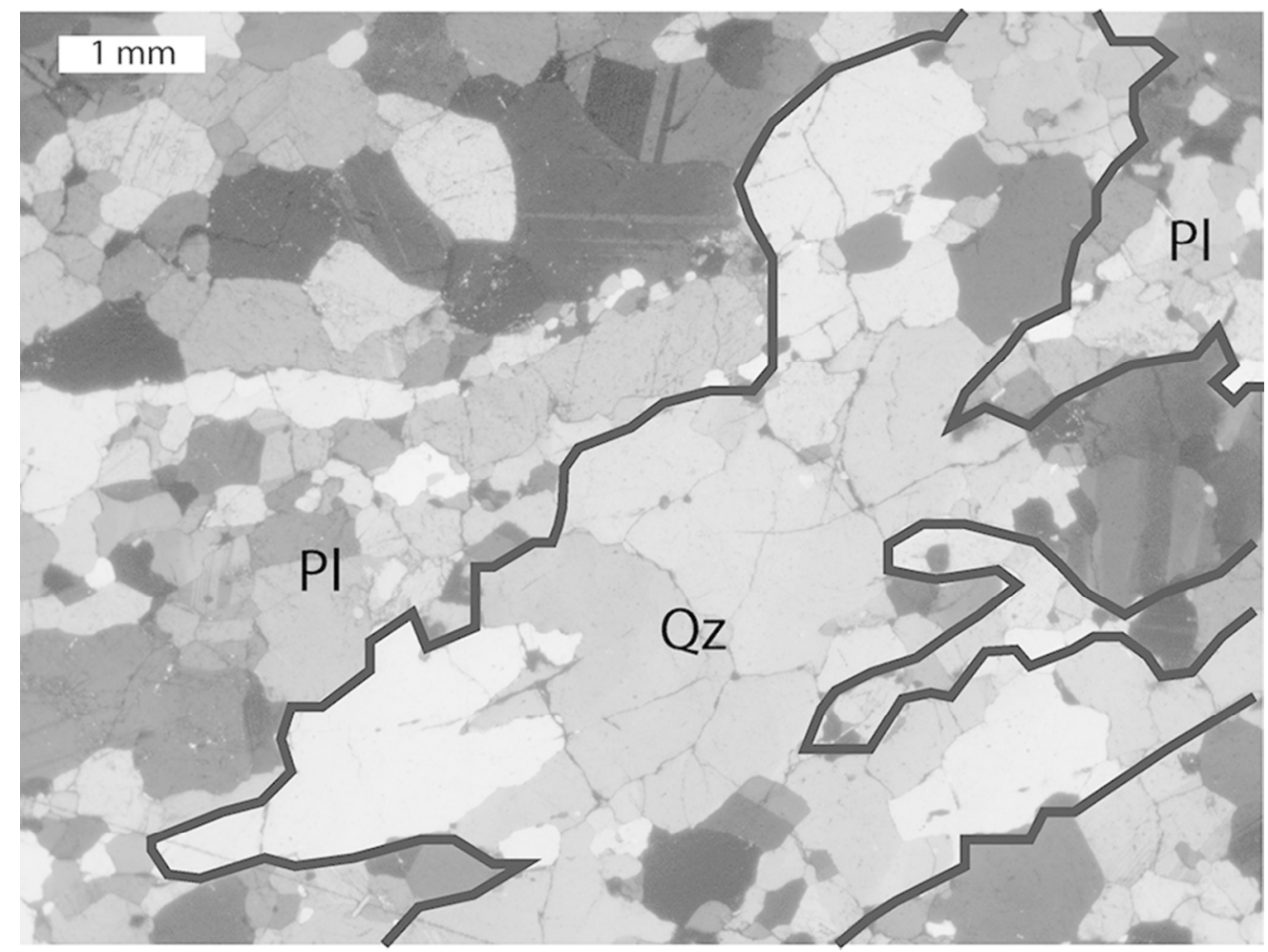

Fig. 4. Quartz aggregate surrounded by plagioclase matrix. Plane polarized light. Solid line indicates boundary of quartz aggregate. Mineral abbreviations after Whitney and Evans (2010).

$86 \times 65 \mathrm{~mm}(300 \times 300 \mathrm{DPI})$ 


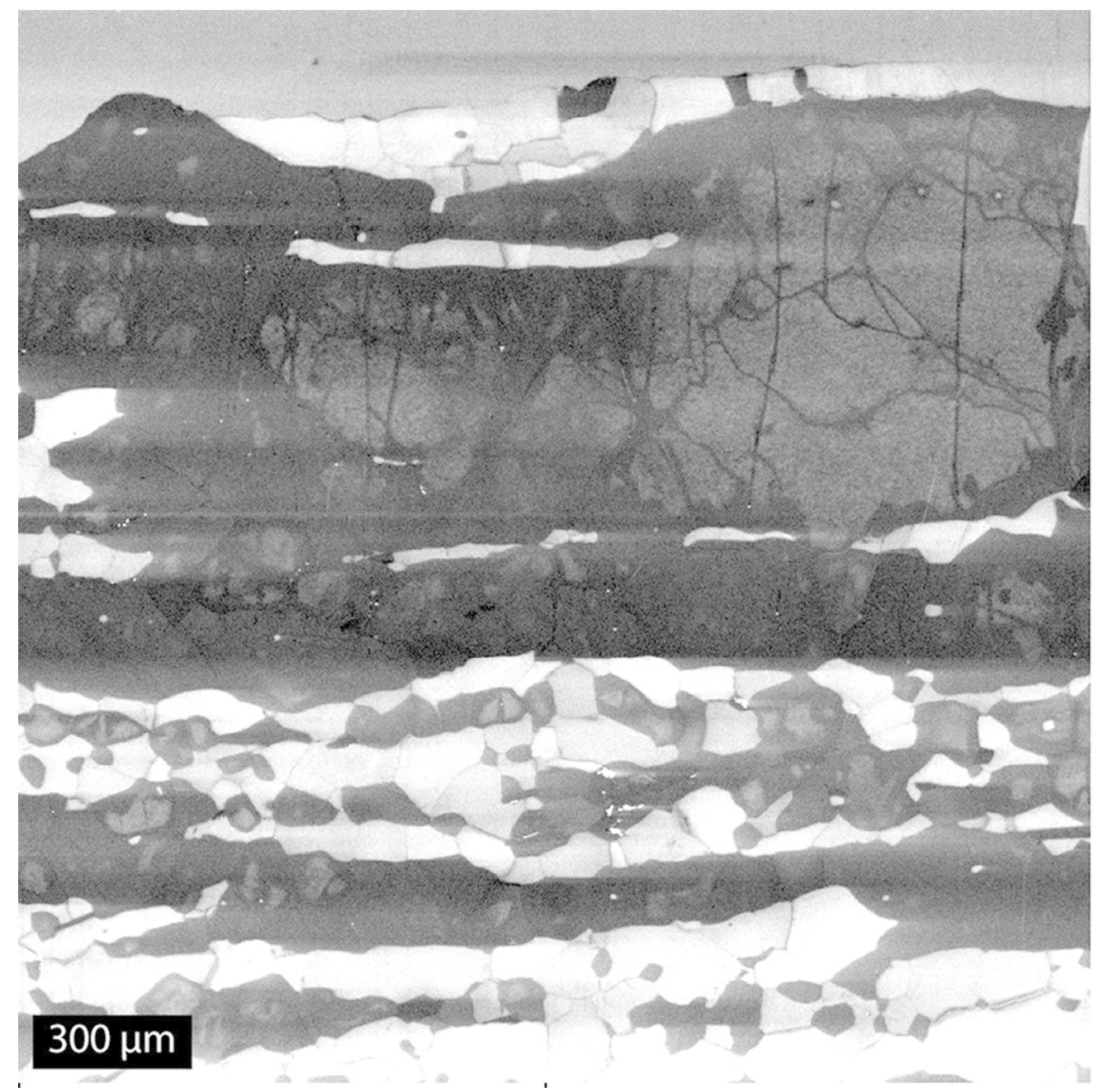

Fig. 5. CL image of medium-dark quartz grains (GB21L; Parry Sound shear zone). Brightness and contrast have been adjusted so that mantles, straight lines and sinuous lines are visible. Bright grains are plagioclase and K-feldspar.

$86 \times 86 \mathrm{~mm}(300 \times 300 \mathrm{DPI})$ 


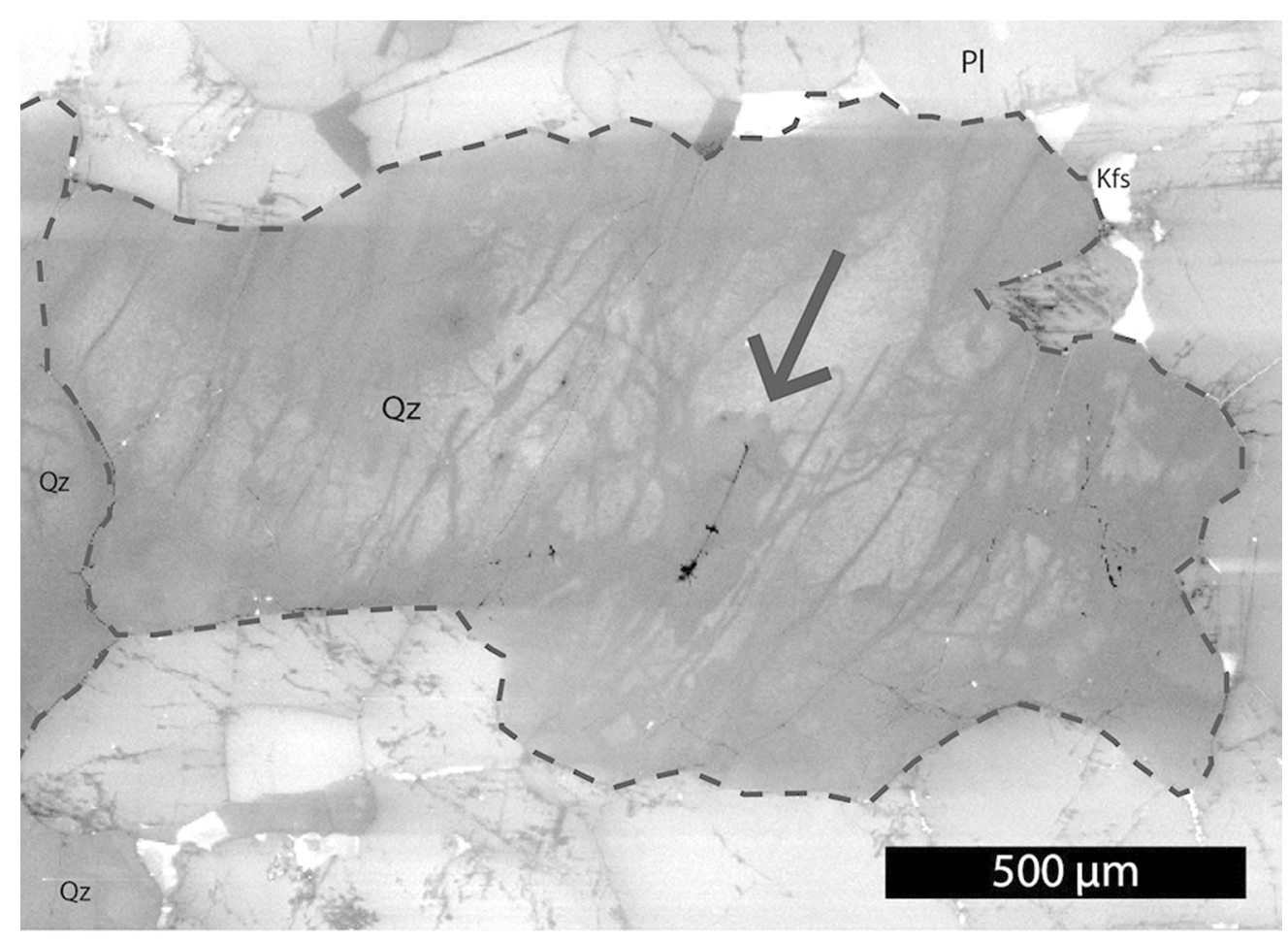

Fig. 6. CL-dark, intragranular patches (arrow) cored by darker lines which are fluid inclusions. These patches have an irregular shape and a radius of $\sim 50-200 \mu \mathrm{m}$ from the dark line, both similar properties to the mantles. Mineral abbreviations after Whitney and Evans (2010).

$86 \times 62 \mathrm{~mm}(300 \times 300$ DPI $)$ 


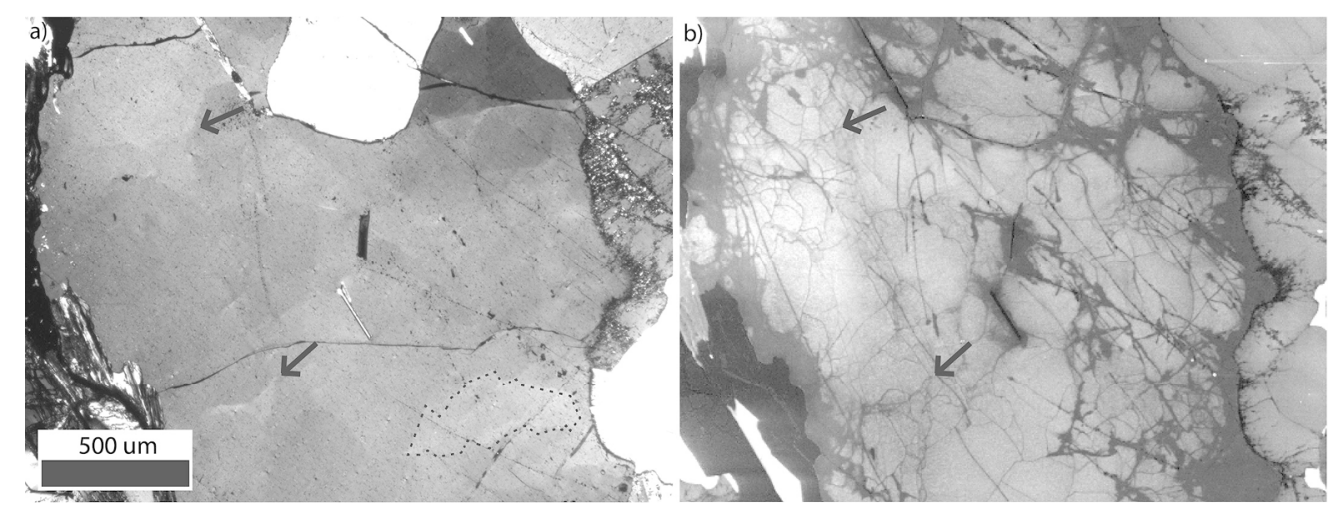

Fig. 7. Typical, irregular quartz subgrain morphology of sample GB61J. (a) Cross-polarized light image; dashed line outlines one subgrain and arrows point to sinuous lines in (b). (b) CL image of the same area in (a); arrows point to some examples of sinuous lines that correspond to subgrain boundaries in (a). The brighter patch on the left is an artifact of imaging.

$182 \times 68 \mathrm{~mm}(300 \times 300 \mathrm{DPI})$ 

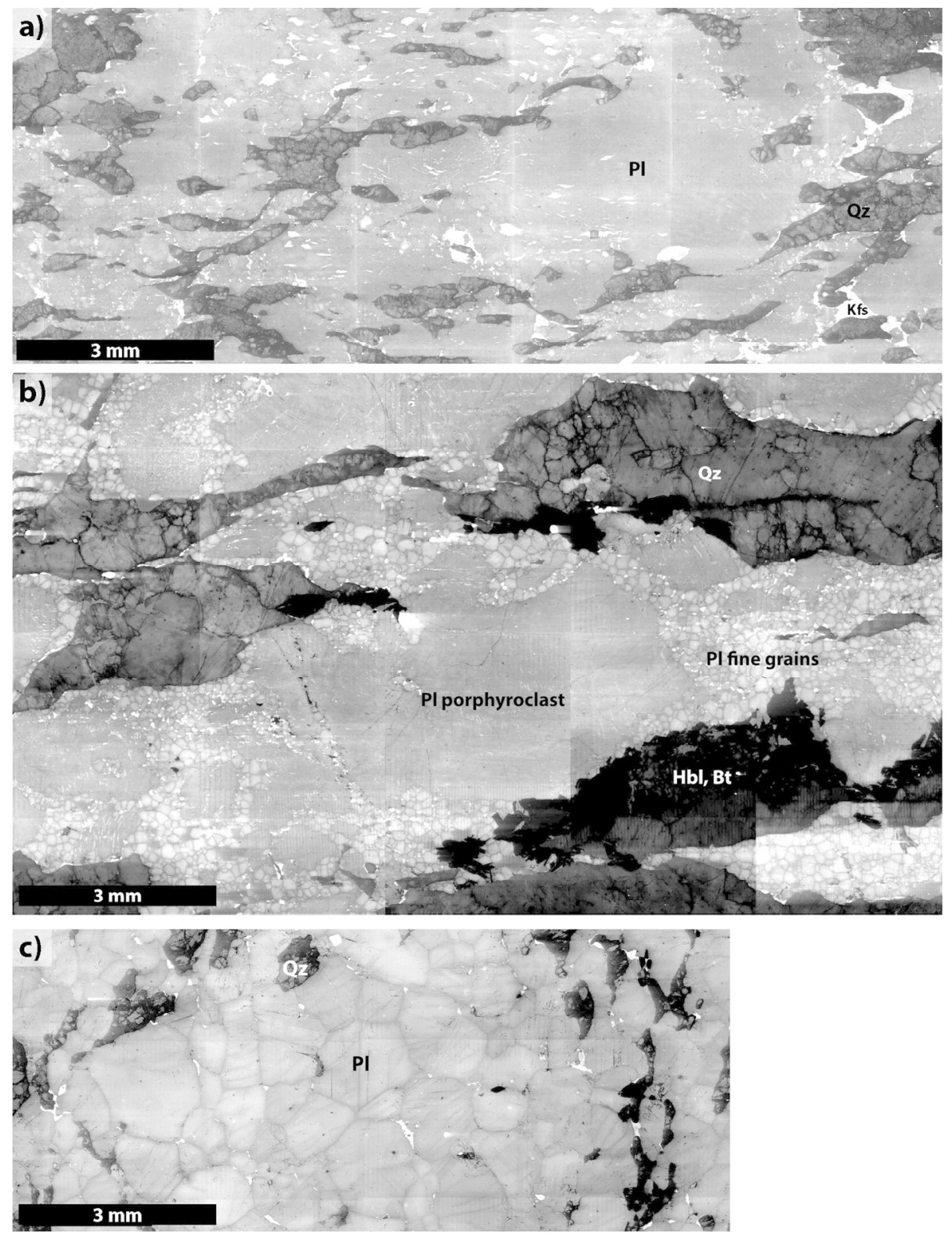

Fig. 8. CL images of feldspar textures. Vertical and horizontal lines are an artifact of scanning and stitching several images together. (a) Sample GB61G, large antiperthitic grains in protolith; (b) Sample GB55, large antiperthitic grains surrounded by small, brighter $\mathrm{CL}$, equant, polygonal plagioclase in protolith. (c) Sample GB61J medium sized, equant, polygonal plagioclase in sheared sample. Mineral abbreviations after Whitney and Evans (2010).

$179 \times 236 \mathrm{~mm}(300 \times 300$ DPI $)$ 


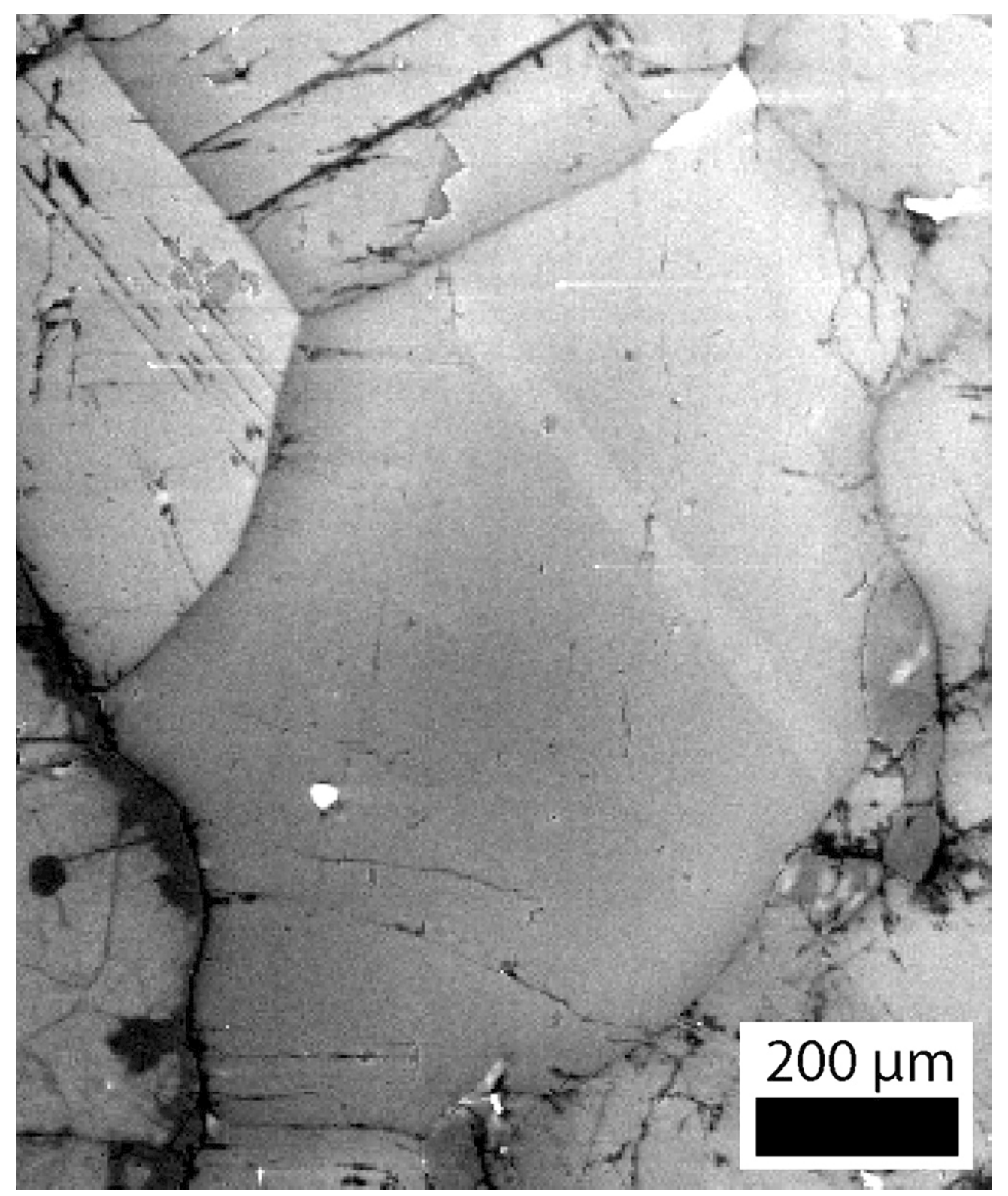

Fig. 9. Recrystallized plagioclase (GB61J) viewed in CL with brightness and contrast adjusted to enhance internal features. Despite the field-wide CL intensity gradient, plagioclase rims are visibly brighter than the core.

$86 \times 103 \mathrm{~mm}(300 \times 300 \mathrm{DPI})$ 

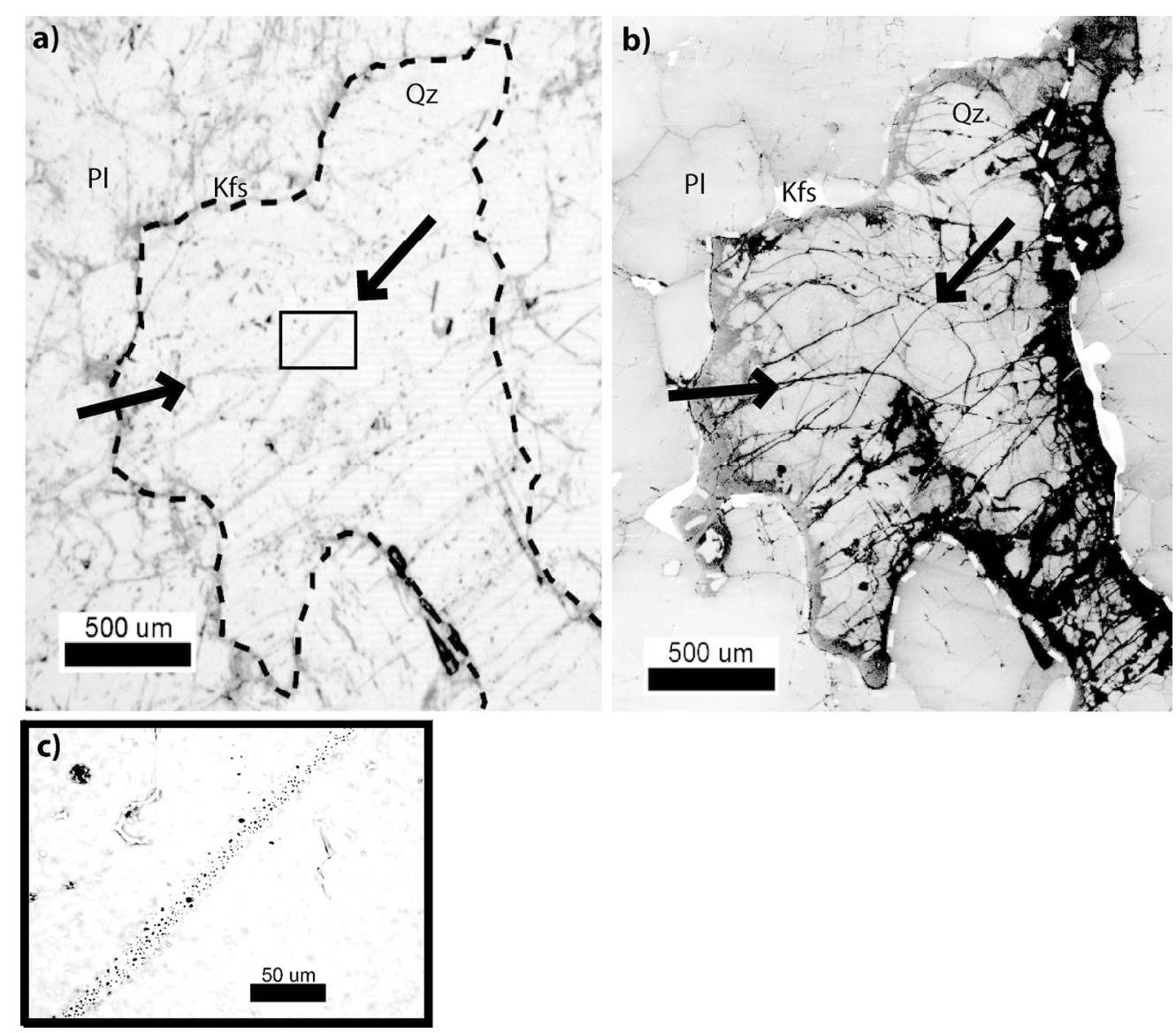

Fig. 10. (a) CL image of straight lines and (b) optical image of fluid inclusion planes at the same locations. Arrows point to the same planes/lines. Dashed line, black in (a) and white in (b), indicates grain boundary. (c) Close-up of fluid inclusions; inset from (a). Mineral abbreviations after Whitney and Evans (2010).

$$
182 \times 160 \mathrm{~mm}(300 \times 300 \mathrm{DPI})
$$



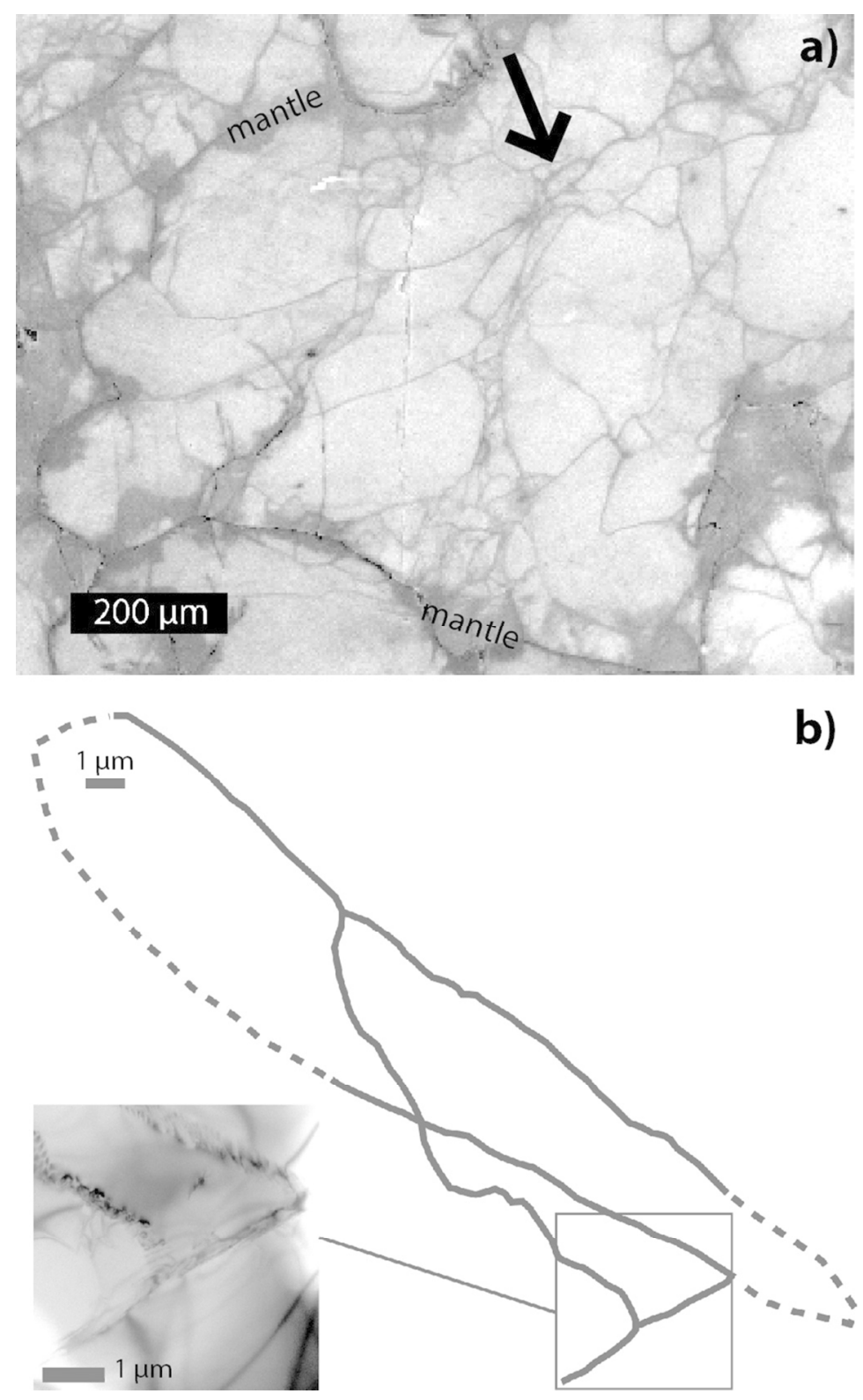

Fig. 11. (a) CL image of area chosen for STEM foil from GB9C. Entire field of view is quartz. Arrow points to many tightly interconnected sinuous lines that are possibly the area imaged in (b). Due to standard STEM sample preparation and handling, it is difficult to know the exact location of (b) on (a). Some mantles are marked, but again we cannot be sure which images incorporated mantle area. (b) Solid lines trace subgrain boundaries that were directly imaged with STEM. Dashed lines indicate regions that were not imaged, so the boundaries are inferred. Imaged subgrain boundaries are the typical regular arrays of dislocations as seen in the representative STEM image.

$86 \times 141 \mathrm{~mm}(300 \times 300 \mathrm{DPI})$ 


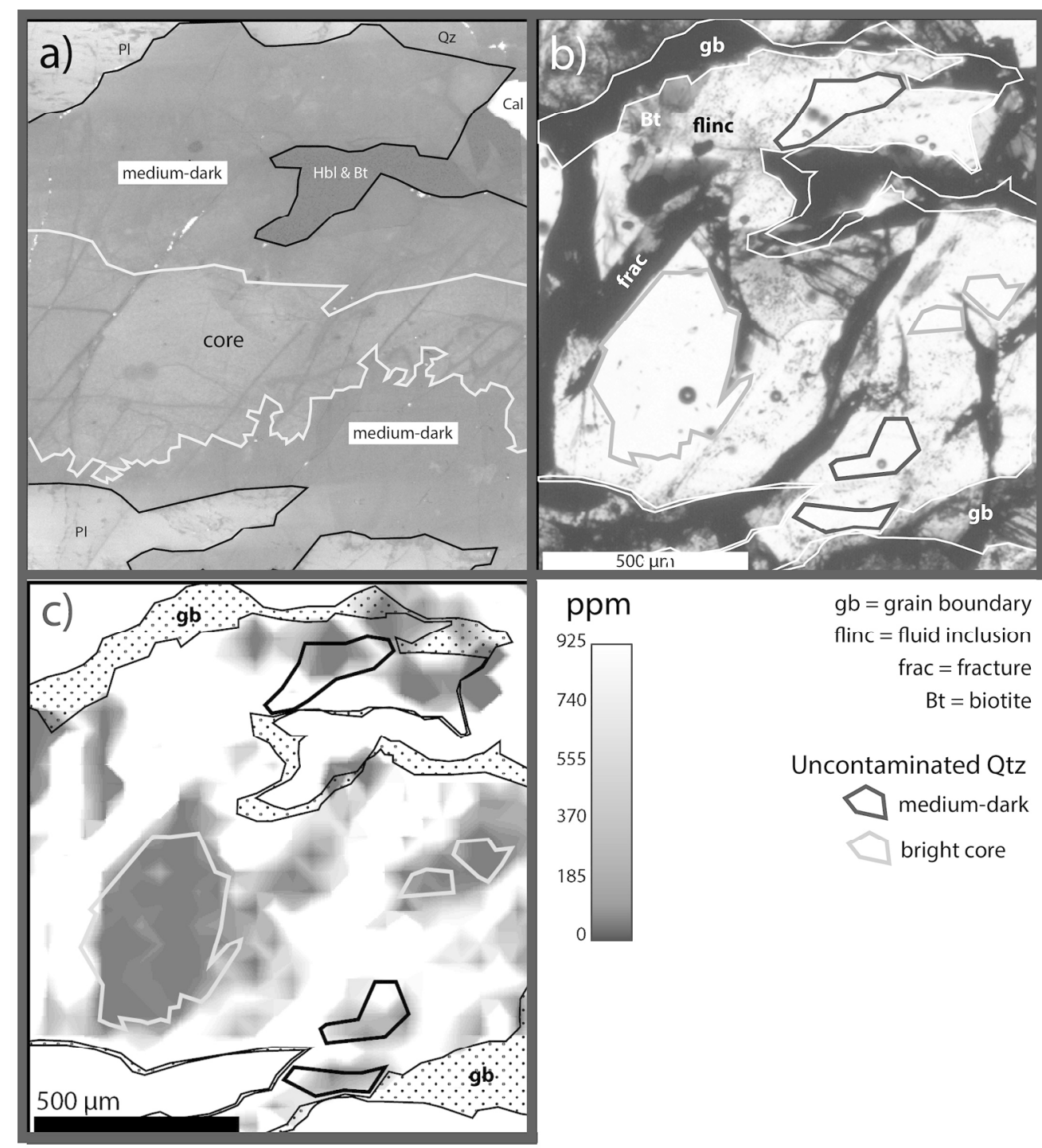

Fig. 12. Area analyzed for water species concentration in quartz. Each panel shows the same area from GB38A. (a) Annotated $\mathrm{CL}$ image discriminating among morphological regions of analyzed area. Areas marked "medium-dark" and "core" are quartz with the light line as the boundary between the microstructures and the black line as the grain boundary. (b) Plane polarized light image showing areas that are contaminated. This section is $\sim 160 \mu \mathrm{m}$ thick, so grain boundaries at an angle appear wide in two dimensions. (c) FTIR map of water species concentration. The scale is only accurate for quartz because a different calibration is required for other minerals. Solid, thick outlines in core and medium-dark areas are of "uncontaminated" intragranular regions free from fractures, fluid inclusions, and portions of adjacent nonquartz minerals. 


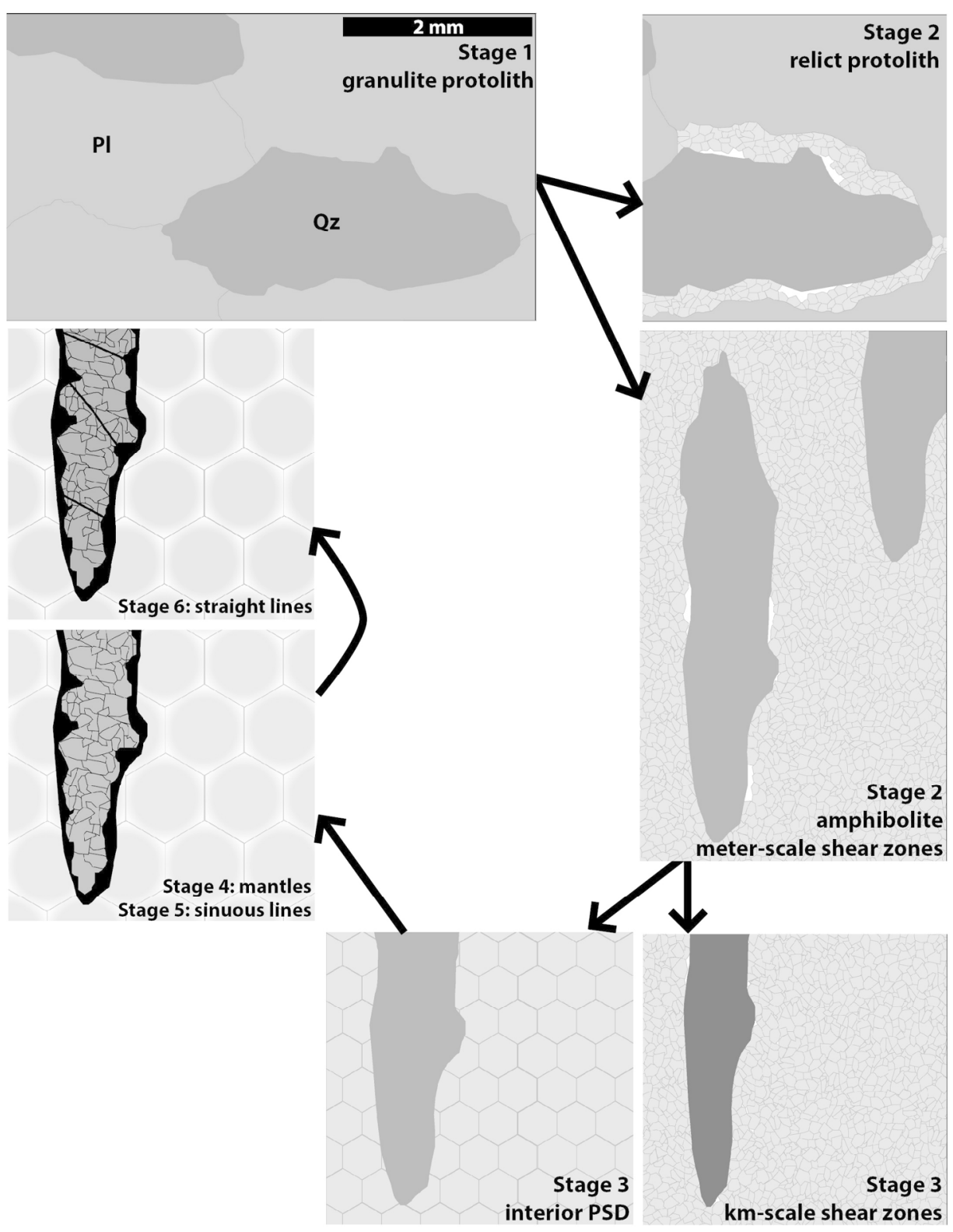

Fig. 13. Schematic illustration of microstructural evolution. Dark grey = quartz, medium grey $=$ relict, antiperthitic plagioclase, light grey = recrystallized plagioclase, black = quartz CL microstructures. All are at the same scale. Stage 1: At granulite facies conditions, felsic layers contain CL-bright quartz and antiperthitic plagioclase grains. Stage 2: After cooling to upper amphibolite facies conditions, quartz domains in the shear zones change orientation and shape yet maintain a bright CL character. Plagioclase recrystallizes to a different grain size and composition. Stage 3: After cooling to lower-amphibolite facies conditions. Where shearing has ceased (left panel), quartz maintains bright CL cores and plagioclase grows to equant, polygonal grains. Where shearing persists (right panel), quartz recrystallizes to medium-dark grains. Stage 4: After shearing ceases everywhere, residual water at the grain boundaries forms dark CL mantles in quartz and bright CL rims in plagioclase. Stage 5: Above $400^{\circ} \mathrm{C}$, sinuous lines (subgrains) form under small amounts of differential stress and low strain. Stage 6: Below $\sim 400^{\circ} \mathrm{C}$, microcracking and healing forms the straight lines (fluid inclusion planes). 
$182 \times 235 \mathrm{~mm}(300 \times 300 \mathrm{DPI})$

https://mc06.manuscriptcentral.com/cjes-pubs 


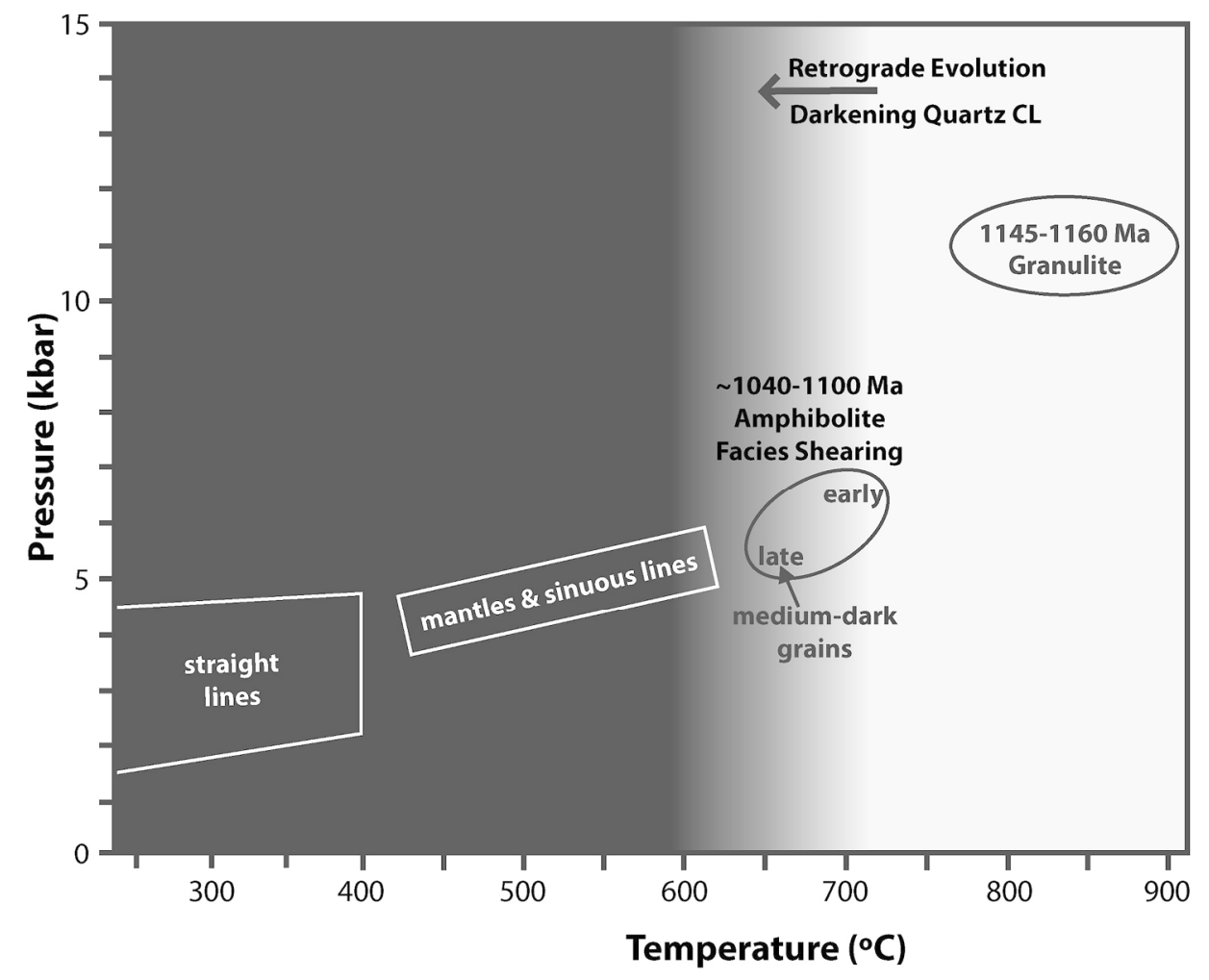

Fig. 14. Pressure-temperature-time path (after Marsh et al., 2013) with quartz CL microstructural events overlain. The CL intensity of the microstructures (grayscale background) reflects the temperature of recrystallization.

$182 \times 140 \mathrm{~mm}(300 \times 300 \mathrm{DPI})$ 